\title{
Adsorption and activation of molecular oxygen over atomic copper (I/II) site on ceria
}

\author{
Liqun Kang (1) 1,18, Bolun Wang 10 1,18,19凶 , Qiming Bing², Michal Zalibera (1) ${ }^{3}$, Robert Büchel ${ }^{4}$, Ruoyu Xu1, \\ Qiming Wang ${ }^{1}$, Yiyun Liu (1) ${ }^{1}$, Diego Gianolio (1) ${ }^{5}$, Chiu C. Tang ${ }^{5}$, Emma K. Gibson (1) ${ }^{6}$, Mohsen Danaie (1) 7,8, \\ Christopher Allen (10 7,8, Ke Wu9 , Sushila Marlow (1) 1, Ling-dong Sun9, Qian He ${ }^{10}$, Shaoliang Guan (i) 5,11, \\ Anton Savitsky ${ }^{12,13}$, Juan J. Velasco-Vélez ${ }^{14}$, June Callison (1) ${ }^{15}$, Christopher W. M. Kay (1) ${ }^{16,17}$, \\ Sotiris E. Pratsinis (D) ${ }^{4}$, Wolfgang Lubitz ${ }^{12}$, Jing-yao Liu² \& Feng Ryan Wang (1) 1,19凶
}

Supported atomic metal sites have discrete molecular orbitals. Precise control over the energies of these sites is key to achieving novel reaction pathways with superior selectivity. Here, we achieve selective oxygen $\left(\mathrm{O}_{2}\right)$ activation by utilising a framework of cerium $(\mathrm{Ce})$ cations to reduce the energy of $3 d$ orbitals of isolated copper $(\mathrm{Cu})$ sites. Operando $\mathrm{X}$-ray absorption spectroscopy, electron paramagnetic resonance and density-functional theory simulations are used to demonstrate that a $\left[\mathrm{Cu}(\mathrm{I}) \mathrm{O}_{2}\right]^{3-}$ site selectively adsorbs molecular $\mathrm{O}_{2}$, forming a rarely reported electrophilic $\eta^{2}-\mathrm{O}_{2}$ species at $298 \mathrm{~K}$. Assisted by neighbouring $\mathrm{Ce}(\mathrm{III})$ cations, $\eta^{2}-\mathrm{O}_{2}$ is finally reduced to two $\mathrm{O}^{2-}$, that create two $\mathrm{Cu}-\mathrm{O}-\mathrm{Ce}$ oxo-bridges at $453 \mathrm{~K}$. The isolated $\mathrm{Cu}(\mathrm{I}) /(\mathrm{II})$ sites are ten times more active in $\mathrm{CO}$ oxidation than $\mathrm{CuO}$ clusters, showing a turnover frequency of $0.028 \pm 0.003 \mathrm{~s}^{-1}$ at $373 \mathrm{~K}$ and $0.01 \mathrm{bar} P_{\mathrm{CO}}$. The unique electronic structure of $\left[\mathrm{Cu}(\mathrm{I}) \mathrm{O}_{2}\right]^{3-}$ site suggests its potential in selective oxidation.

\footnotetext{
${ }^{1}$ Department of Chemical Engineering, University College London, Roberts Building, Torrington Place, London WC1E 7JE, UK. ${ }^{2}$ Laboratory of Theoretical and Computational Chemistry, Institute of Theoretical Chemistry, Jilin University, Changchun, Jilin 130023, P. R. China. ${ }^{3}$ Institute of Physical Chemistry and Chemical Physics, Slovak University of Technology in Bratislava, Faculty of Chemical and Food Technology, Radlinského 9, 81237 Bratislava, Slovak Republic. ${ }^{4}$ Particle Technology Laboratory, Institute of Process Engineering, Department of Mechanical and Process Engineering, ETH Zürich, 8092 ,

Zürich, Switzerland. ${ }^{5}$ Diamond Light Source Ltd., Harwell Science and Innovation Campus, Chilton, Didcot OX11 ODE, UK. ${ }^{6}$ School of Chemistry, University of Glasgow, Joseph Black Building. University Avenue, Glasgow G12 8QQ, UK. ${ }^{7}$ Electron Physical Science Imaging Center, Diamond Light Source Ltd., Didcot OX11 ODE, UK. ${ }^{8}$ Department of Materials, University of Oxford, Parks Road, Oxford OX1 3PH, UK. ${ }^{9}$ College of Chemistry and Molecular Engineering, Peking University, Beijing, P. R. China. ${ }^{10}$ Department of Materials Science and Engineering, National University of Singapore, Singapore 117575, Singapore. ${ }^{11}$ HarwellXPS-The EPSRC National Facility for Photoelectron Spectroscopy, Research Complex at Harwell (RCaH), Didcot OX11 OFA, UK. ${ }^{12}$ Max-PlanckInstitut Für Chemische Energiekonversion, Stiftstrasse 34-36, D-45470 Mülheim an der Ruhr, Germany. ${ }^{13}$ Department of Physics, Technical University of Dortmund, 44221 Dortmund, Germany. ${ }^{14}$ Fritz-Haber-Institut der Max-Planck-Gesellschaft, Faradayweg 4-6, 14195 Berlin, Germany. ${ }^{15}$ UK Catalysis Hub, Research Complex at Harwell (RCaH), Rutherford Appleton Laboratory, Harwell OX11 OFA, UK. ${ }^{16}$ London Centre for Nanotechnology, University College London, 17-19 Gordon Street, London WC1H OAH, UK. ${ }^{17}$ Department of Chemistry, University of Saarland, 66123 Saarbrücken, Germany. ${ }^{18}$ These authors contributed equally: Liqun Kang, Bolun Wang. ${ }^{19}$ These authors jointly supervised this work: Bolun Wang, Feng Ryan Wang. ${ }^{凶}$ email: bolun.wang@ucl.ac.uk; ryan.wang@ucl.ac.uk
} 
$\mathrm{M}$ olecular $\mathrm{O}_{2}$ is the simplest and most abundant oxidant for combustion, oxidation and electrochemical reactions. The $\mathrm{O}_{2}$ activation pathway depends on the nature of the catalytic active site, which often involves $d$-block metals due to their rich oxidation states and variable coordination geometries $^{1}$. In an electrochemical oxygen reduction reaction, an optimal position for the $d$-band centre of the metal is required for both adsorption of $\mathrm{O}_{2}$ and cleavage of the $\mathrm{O}=\mathrm{O}$ bond $^{2}$. Hence, group 10 metals and alloys, such as $\mathrm{Pt}$ and Pd, are a standard choice $^{3-5}$. In comparison, when considering selective oxidation, metals with lower $d$-band centres, such as group 11 metals, are preferred $^{6-8}$. Typically, $\mathrm{O}_{2}$ weakly adsorbs on these metal surfaces, forming superoxide $\mathrm{O}_{2}{ }^{-}$and peroxide $\mathrm{O}_{2}{ }^{2-}$. Gold and its alloys with $\mathrm{Pd}$ can form $\mathrm{H}_{2} \mathrm{O}_{2}$ in situ and subsequently activate the $\mathrm{C}-\mathrm{H}$ bond ${ }^{9,10}$ while large $\mathrm{Ag}$ nanoparticles are the commercial catalyst for the epoxidation of ethylene ${ }^{11}$. The first group 11 metal, $\mathrm{Cu}$, has a higher $d$-band centre than both $\mathrm{Au}$ and $\mathrm{Ag}^{12,13}$. As a result, $\mathrm{Cu}$ is mainly used for the total oxidation of $\mathrm{CO}^{14-16}$ and $\mathrm{NH}_{3}$ oxidation with $\mathrm{NO}^{17-19}$. The redox reaction of $\mathrm{Cu}(\mathrm{I}) / \mathrm{Cu}(\mathrm{II})$ involves a transition between $d^{10}$ and $d^{9}$ electron configurations, which is rarely seen in the periodic table and is key to the high oxidation activity and selectivity. Unlike Au and $\mathrm{Ag}$, the $\mathrm{Cu}$ based peroxide $\mathrm{O}_{2}{ }^{2-}$ and superoxide $\mathrm{O}_{2}{ }^{-}$systems are mainly found in homogeneous catalysis ${ }^{20-22}$, where $1: 1 \mathrm{Cu}$ : $\left(\eta^{2}-\mathrm{O}_{2}\right)$ single-site complexes are present in nature or synthetically made for $\mathrm{Cu}$-mediated catalysis ${ }^{23-25}$.

The surface atomic metal site has discrete electronic structures compared with the continuous band structures found in clusters $^{26,27}$. Their interactions with reactants are based on their structure and energy match. The supporting cation, $\mathrm{Ce}^{4+}$, can withdraw electrons from $\mathrm{Cu}$ to reduce its $d$-band centre, enhancing the electrophilicity of the $\mathrm{Cu}$ species $^{28}$. This electron withdrawing effect is strengthened by increasing the number of $\mathrm{Ce}^{4+}$ ions per $\mathrm{Cu}$ site. The energy splitting between the highest occupied molecular orbital (HOMO) and the lowest unoccupied molecular orbital (LUMO) of $\mathrm{Cu}$ species is therefore increased by the interaction between $\mathrm{Cu}$ and $\mathrm{Ce}$ (Fig. 1), and is maximised in isolated and atomically dispersed $\mathrm{Cu}$ sites, which have the lowest possible HOMO. Recently, such a discrete electronic structure was demonstrated in the $\mathrm{Ag} / \mathrm{Cu}$ system, in which the $\mathrm{Cu} d$ states were nearly unperturbed from their free-atom state ${ }^{29}$. In the $\mathrm{Cu} /$ $\mathrm{TiO}_{2}$ system, the atomic $\mathrm{Cu}$ site can reversibly modulate the

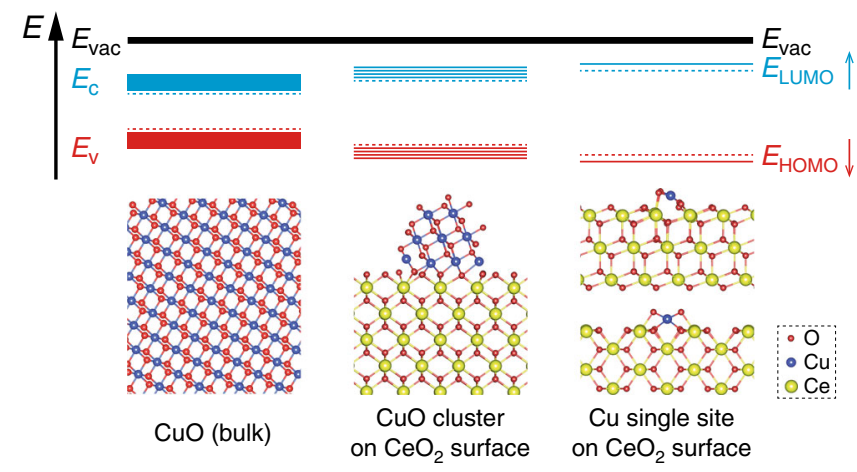

Fig. 1 Schematic of electron withdrawing effect from $\mathrm{Ce}^{4+}$. From bulk $\mathrm{CuO}$ to atomic $\mathrm{Cu}(\mathrm{I} / \mathrm{II})$ site, continuous band structure becomes discrete molecular orbitals. $E_{\mathrm{vac}}, E_{\mathrm{c}}, E_{\mathrm{v}}, E_{\mathrm{LUMO}}$ and $E_{\mathrm{HOMO}}$ represent for the energy level of vacuum, conductive band, valence band, LUMO and HOMO, respectively. The HOMO and LUMO gap increased in comparison between bulk and atomic $\mathrm{Cu}(\mathrm{I} / \mathrm{II})$ site. This is indicated by the study of occupied $3 d$ orbitals and unoccupied $4 p$ orbitals energy levels, respectively. The schematic structures illustrate the atomic $\mathrm{Cu}(\mathrm{I} / \mathrm{II})$ site concept and do not represent the real surface species. macroscopic optoelectronic properties of $\mathrm{TiO}_{2}$, enhancing the photocatalytic hydrogen evolution activity ${ }^{30}$. Thus, the ability to precisely control the electronic structures of atomic sites is important to achieve the desired reaction pathway.

As part of our search for catalytic active centres in selective $\mathrm{O}_{2}$ adsorption and activation towards electrophilic or nucleophilic oxygen species ${ }^{31,32}$, here we report controlling the electronic structures of atomic $\mathrm{Cu}(\mathrm{I}) / \mathrm{Cu}(\mathrm{II})$ sites via $\mathrm{CeO}_{2}$ surface. The neighbouring $\mathrm{Ce}^{4+}$ lowers the occupied $3 d$ orbital energy of atomically isolated $\mathrm{Cu}(\mathrm{II})$ by $0.7 \mathrm{eV}$, as shown in results from $\mathrm{X}$ ray absorption near edge structure (XANES). In comparison, the energy of the unoccupied $4 p_{z}$ orbitals increases by $2.2 \mathrm{eV}$ from $\mathrm{CuO}$ clusters to atomic $\mathrm{Cu}(\mathrm{II})$ site. The change in the electronic structure leads to the formation of an electrophilic [Cu(II) $\left.\mathrm{O}_{2}\left(\eta^{2}-\mathrm{O}_{2}\right)\right]^{4-}$ site upon $\mathrm{O}_{2}$ adsorption, as confirmed via near ambient pressure-near edge $\mathrm{X}$-ray absorption fine structure (NAP-NEXAFS) and Raman spectroscopy supported by spinpolarised density functional theory (DFT) calculations. With quantified density of the surface atomic $\mathrm{Cu}(\mathrm{II})$ at 1 site per $5 \mathrm{~nm}^{2}$ by electron paramagnetic resonance (EPR) spectroscopy, the activity of atomic $\mathrm{Cu}(\mathrm{I} / \mathrm{II})$ site in model $\mathrm{CO}$ oxidation is directly correlated to its quantitative electronic structures.

\section{Results}

Identifying the highest density of atomic $\mathrm{Cu}(\mathrm{II})$ site. FSP is used to obtain atomic $\mathrm{Cu}$ (II) site and clusters supported on $\mathrm{CeO}_{2}$ nanoparticles with small particle sizes $(3-5 \mathrm{~nm}$ ) (Supplementary Figs. 1 and 2) and high surface area up to $220 \mathrm{~m}^{2} / \mathrm{g}^{33,34}$. The pyrolysis of $\mathrm{Cu}$ and $\mathrm{Ce}$ forms uniformly distributed $\mathrm{Cu}$ species on $\mathrm{CeO}_{2}$ owing to simultaneous $\mathrm{CeO}_{2}$ crystallisation and $\mathrm{Cu}$ site formation. Due to the low $\mathrm{Z}$-contrast of $\mathrm{Cu}$ compared with $\mathrm{Ce}$, $\mathrm{Cu}$ species are difficult to observe in high resolution aberrationcorrected high angle annular dark field-scanning transmission electron microscopy (HAADF-STEM) (Fig. 2a). The presence of $\mathrm{Cu}$ is confirmed by energy-dispersive X-ray spectroscopy (EDS) $(\mathrm{Cu}$ peak in Supplementary Fig. 2b). Element mapping shows a uniform distribution of $\mathrm{Cu}$ and $\mathrm{Ce}$ at $1 \mathrm{wt} \% \mathrm{CuO}$ loading (Fig. 2b). Increasing the $\mathrm{CuO}$ loading causes aggregation of $\mathrm{Cu}$ species (white circle in Supplementary Fig 3c, d). Synchrotron Xray diffraction (SXPD) shows the presence of small crystalline $\mathrm{CuO}$ particles in $20 \mathrm{wt} \% \mathrm{CuO}-\mathrm{CeO}_{2}$ (Supplementary Fig. 4).

The structure of atomic $\mathrm{Cu}$ site is revealed in the EXAFS study. Below $1 \mathrm{wt} \% \mathrm{CuO}$ loading, the EXAFS show a similar $\mathrm{Cu}-\mathrm{O}$ scattering at $1.95 \pm 0.01 \AA$ with coordination numbers between $3.70 \pm 0.24$ and $4.07 \pm 0.15$ (Fig. 2c; Supplementary Fig. 6; Supplementary Table 1). There is no $\mathrm{Cu}-\mathrm{Cu}$ scattering, indicating the atomic isolation of $\mathrm{Cu}$ sites. Above $10 \mathrm{wt} \%, \mathrm{Cu}-\mathrm{Cu}$ scattering appears at $2.87 \pm 0.04 \AA(\mathrm{Cu}-\mathrm{Cu}(1))$ and $3.12 \pm 0.02 \AA(\mathrm{Cu}-\mathrm{Cu}$ (2)) (Fig. 2d; Supplementary Table 1), corresponding well to the scattering in standard $\mathrm{CuO}$ crystals (Supplementary Table 1). At the near edge, XANES shows the $1 s \rightarrow 3 d$ quadruple-allowed transitions for all samples from $20 \mathrm{wt} \%$ to $0.05 \mathrm{wt} \% \mathrm{CuO}$ loading, suggesting a majority of $\mathrm{Cu}(\mathrm{II})$ species (Fig. 2e; Supplementary Fig. 5) 35,36 . The absorption energy of $1 s \rightarrow 3 d$ transitions decreases from $8977.2 \mathrm{eV}$ at $20 \mathrm{wt} \%$ to $8976.5 \mathrm{eV}$ below $1 \mathrm{wt} \%$, while the $\mathrm{CuO}$ standard gives $8977.1 \mathrm{eV}$. The reduced adsorption energy at low loadings suggests a decrease of the $3 d$ orbital energy for atomic $\mathrm{Cu}(\mathrm{II})$ site. The $\mathrm{Cu}(\mathrm{II})$ site has the $3 d^{9}$ configuration with four $\mathrm{O}^{2-}$ ligands. The absorption of $1 s \rightarrow 3 d$ depends on the energy level of the half-empty orbital which is the only destination of the excited electron to $3 d$ orbitals. This is considered to be the HOMO or the singly occupied molecular orbital. In comparison to $\mathrm{CuO}$ clusters and bulk $\mathrm{CuO}$, the absorption energies for the $1 s \rightarrow 4 p_{z}$ (i.e., the shakedown peak from ligand-to-metal charge transfer) and $1 s \rightarrow 4 p_{x y}$ transition 
a
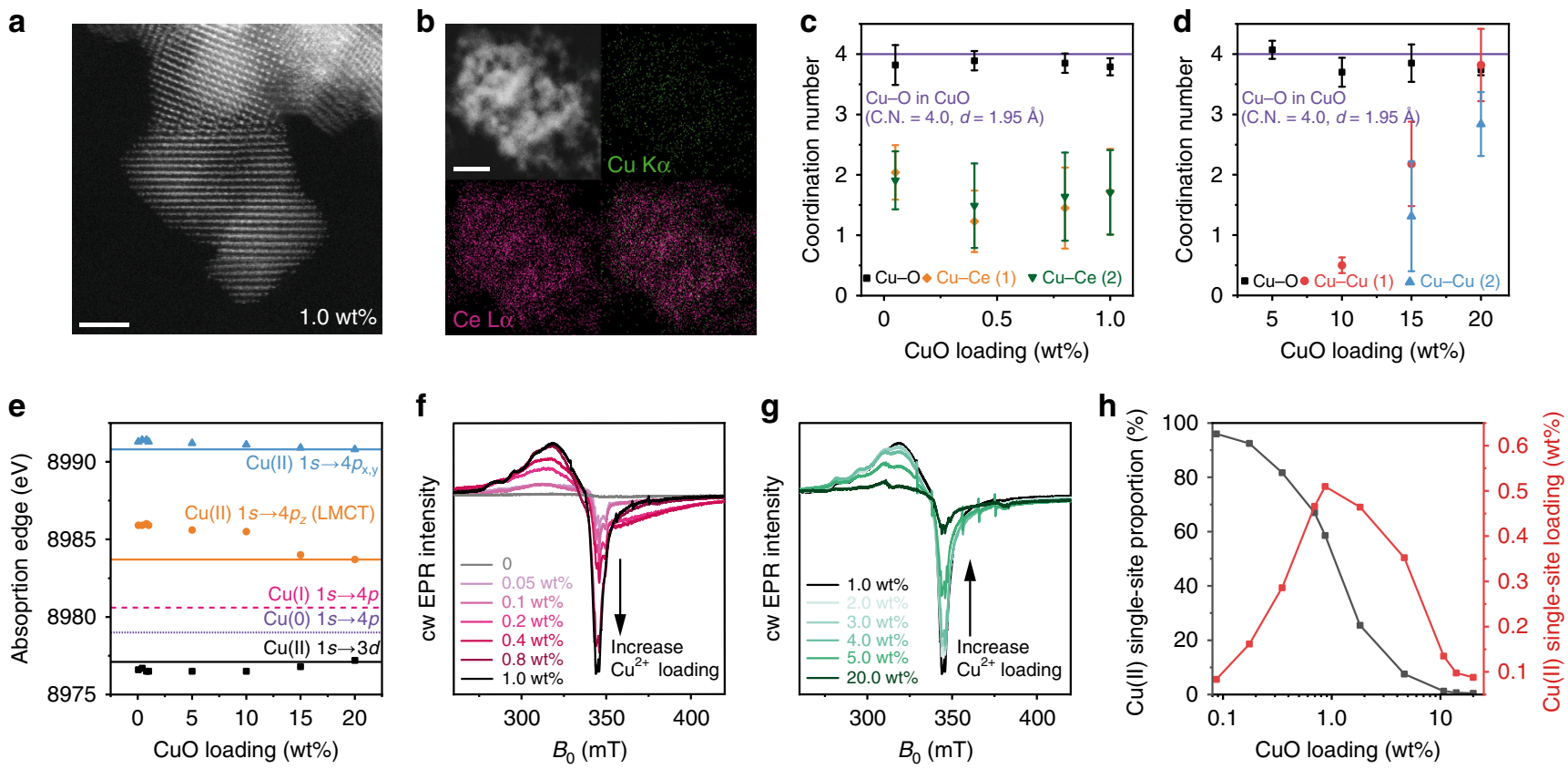

Fig. 2 Structure and quantification of atomic $\mathbf{C u}(\mathrm{II})$ site. a HAADF-STEM images of $\mathrm{CuO}-\mathrm{CeO}_{2}$ at $1 \mathrm{wt} \% \mathrm{CuO}$ loading. $\mathbf{b}$ EDS mapping of the $\mathrm{CuO}-\mathrm{CeO}{ }_{2}$ at 1 wt $\% \mathrm{CuO}$ loading with red for $\mathrm{Ce}$ and green for $\mathrm{Cu}$. c, d The coordination numbers (C.N.) of $\mathrm{Cu}-\mathrm{O}, \mathrm{Cu}-\mathrm{Ce}(1), \mathrm{Cu}-\mathrm{Ce}(2), \mathrm{Cu}-\mathrm{Cu}(1)$ and $\mathrm{Cu}-\mathrm{Cu}(2)$ scattering as a function of $\mathrm{Cu}$ loading, derived from the EXAFS spectra. Purple line: The $\mathrm{Cu}-\mathrm{O}$ coordination number is 4 in the $\mathrm{CuO}$ standard. The standard error of the mean (s.e.m.) is labelled according to the EXAFS fitting results listed in Supplementary Table 1. e The peak position of $1 s \rightarrow 3 d$ and $1 s \rightarrow 4 p$ electron transitions in the first derivative of $\mathrm{Cu}$ K-edge XANES, showing changes of absorption energy as a function of Cu loading compared to metallic Cu (purple line), $\mathrm{Cu}_{2} \mathrm{O}$ (pink line) and $\mathrm{CuO}$ (black, orange and blue lines) as standard materials. $\mathbf{f} \mathrm{X}$-band cw EPR spectra for $\mathrm{CuO}^{-} \mathrm{CeO} 2$ with $\mathrm{CuO}_{2}$ loading from $\mathrm{O}$ to $1 \mathrm{wt} \%$. $\mathbf{g}$ EPR spectra for $\mathrm{CuO}-\mathrm{CeO}_{2}$ with $\mathrm{CuO}$ loading from 1 to 20 wt\%. h Quantification of atomic $\mathrm{Cu}$ (II) site. Black: molar proportion of atomic $\mathrm{Cu}(\mathrm{II})$ site within all $\mathrm{Cu}$ species in $\mathrm{CuO}-\mathrm{CeO}_{2}$. Red: absolute loading of atomic $\mathrm{Cu}$ (II) site showing the optimal content at $1 \mathrm{wt} \%$. Scale bars: $2 \mathrm{~nm}$ in (a) and $10 \mathrm{~nm}$ in (b).

rise with less $\mathrm{CuO}$ loading, up to 2.2 and $0.5 \mathrm{eV}$, respectively, indicating an increase of the unoccupied $4 p$ orbital energy for atomic $\mathrm{Cu}(\mathrm{II})$ site (Fig. 2e; Supplementary Fig. 5). High energy resolution fluorescence detected XANES (HERFD-XANES) is performed to validate such change of $1 s \rightarrow 3 d, 1 s \rightarrow 4 p_{x y}$ and $1 s \rightarrow 4 p_{z}$ energy from clusters to atomic sites, showing the similar trend (Supplementary Fig. 5e, f; Supplementary Table 2). Thus, the decrease of $\mathrm{CuO}$ size leads to the stronger interaction between $\mathrm{Cu}-\mathrm{O}-\mathrm{Ce}$ and less interaction between $\mathrm{Cu}-\mathrm{O}-\mathrm{Cu}$, increasing the gap between HOMO and LUMO. The change of white line position from 1 to $20 \mathrm{wt} \%$ shows the same trend as that of the $4 p$ orbitals (Supplementary Table 2). The XANES study proves the assumption that $\mathrm{Ce}^{4+}$ reduces the HOMO of atomic $\mathrm{Cu}$ (II) site and increases the energy of its $4 p$ orbitals (Fig. 1).

The $\mathrm{Cu}(\mathrm{II})$ has a $d^{9}$ configuration and is, therefore, EPR active. With increasing $\mathrm{Cu}$ loading, the EPR spectra show signals characteristic of predominantly isolated $\mathrm{Cu}$ (II) species of an axial symmetry with $g_{\|}>g_{\perp}>g_{\mathrm{e}}$ (Fig. 2f). The EPR spectra are representative for composite signals indicating atomic $\mathrm{Cu}$ (II) sites are in different coordination environments. The spectrum of $0.05 \mathrm{wt} \% \mathrm{CuO}-\mathrm{CeO}_{2}$, shows two resolved species with $g_{\|}=2.327$, $g_{\perp}=2.048, A_{\|}=372 \mathrm{MHz}, A_{\perp}=55 \mathrm{MHz}$ and $g_{\|}=2.293, g_{\perp}=$ 2.036, $A_{\|}=402 \mathrm{MHz}, A_{\perp}=92 \mathrm{MHz}$ (signals A1 and C1, respectively ${ }^{37-40}$, Supplementary Fig. 7; Supplementary Note 1; Supplementary Table 3), superimposed on a broader virtually isotropic line with $\langle g\rangle=2.1$ (signal $\mathrm{B} 1$ ). With increasing $\mathrm{CuO}$ loading, from 0.4 up to $1 \mathrm{wt} \%$, a poorly resolved signal with extrema at $g=2.21$ and 2.05 becomes dominant (Fig. 2f, and signal B2 in Supplementary Fig. 8) ${ }^{16,41}$. The Spin Hamiltonian parameters of the resolved signals $\mathrm{A} 1$ and $\mathrm{C} 1$, agree with a $d_{\mathrm{x} 2-\mathrm{y} 2}$ electronic ground state assigned to isolated atomic $\mathrm{Cu}(\mathrm{II})$ site in tetragonally distorted octahedral due to Jahn-Teller effect and square planar coordination of oxygen ligands, respectively $16,41,42$. Signals B1 and B2, showing averaged $\langle\mathrm{g}\rangle$ values close to the signal of $\mathrm{C} 1$, also originate from the $\mathrm{Cu}$ (II) with (distorted) square planar geometry. It is proposed that these signals stem from $[\mathrm{Cu}$ (II) $\left.\mathrm{O}_{4}\right]^{6-}$, which is supported by the XAFS data. The larger linewidth has been previously attributed to dipolar broadening effects in a $\mathrm{Cu}(\mathrm{II})$-containing aggregated phase of an oxidative type ${ }^{16,41}$. However, since no zero field splitting is resolved in these spectra, the dipolar interactions are likely of a long-range character (with a $\mathrm{Cu}-\mathrm{Cu}$ distance $>8 \AA$ ), and such geometric arrangements are not detected in XAFS. The simulated EPR components indicate the presence of at least two types of isolated atomic $\mathrm{Cu}(\mathrm{II})$ sites with one additional site having long-range spin interactions. Such composite spin states, which are not distinguishable in X-ray based techniques, suggest a certain heterogeneity of surface structures.

Using dilute $\mathrm{CuSO}_{4} \cdot 5 \mathrm{H}_{2} \mathrm{O}$ in $\mathrm{Na}_{2} \mathrm{SO}_{4}$ as an external standard ${ }^{18,43}$, we quantified the atomic $\mathrm{Cu}$ (II) site content as a function of the $\mathrm{CuO}$ loading with EPR spectroscopy (Fig. 2h). Nearly $100 \%$ of the $\mathrm{Cu}$ is in the form of atomic $\mathrm{Cu}$ (II) site at 0.05 and $0.1 \mathrm{wt} \%$ loading. The molar proportion of isolated $\mathrm{Cu}(\mathrm{II})$ reaches $58 \%$ at $1 \mathrm{wt} \%$ of $\mathrm{CuO}-\mathrm{CeO}_{2}$, giving the highest absolute atomic site loading. Giving the surface area of $220 \mathrm{~m}^{2} / \mathrm{g}$, a maximum density is calculated as 1 site per $5 \mathrm{~nm}^{2} \mathrm{CeO}_{2}$ surface. The density is significantly reduced above $1 \mathrm{wt} \%$ of $\mathrm{CuO}-\mathrm{CeO}_{2}$, and approaching 0 for $20 \mathrm{wt} \% \mathrm{CuO}-\mathrm{CeO}_{2}$.

CO oxidation activity with atomic $\mathrm{Cu}$ site. With quantified atomic $\mathrm{Cu}(\mathrm{II})$ site loading, we investigate the relationship between the absolute atomic $\mathrm{Cu}(\mathrm{II})$ site content and the catalytic activity in model CO oxidation. We also compared the different 

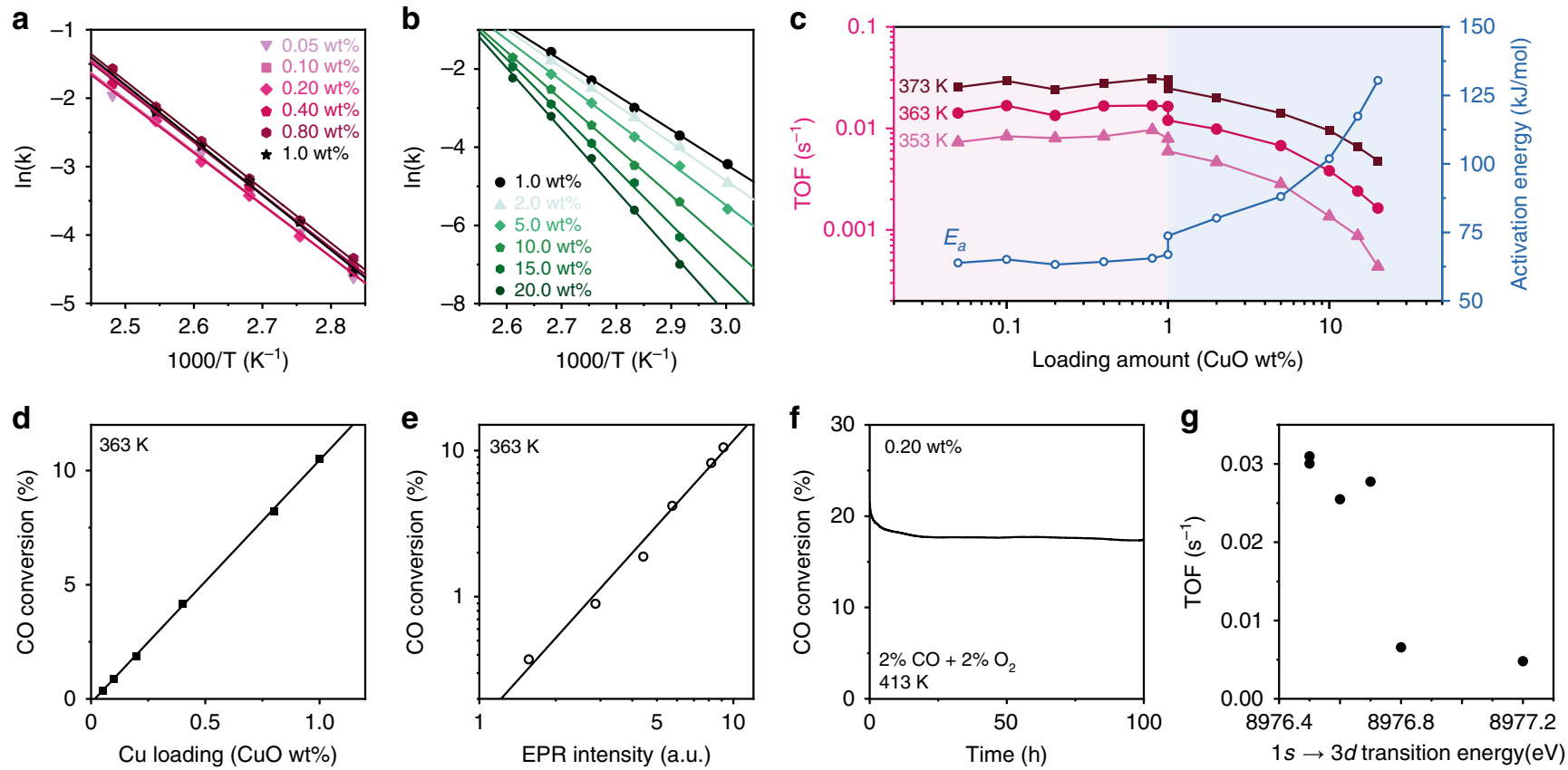

Fig. 3 Catalytic evaluation of Cu species in CO oxidation. a Arrhenius plots at WHSV $=750,000 \mathrm{~mL}_{\mathrm{CO}} \mathrm{h}^{-1} \mathrm{~g}_{\mathrm{CuO}}{ }^{-1}$ for Cu species ranging from 0.1 to $1 \mathrm{wt}$ $\%$. b Arrhenius plots at WHSV $=120,000 \mathrm{~mL}_{\mathrm{CO}} \mathrm{h}^{-1} \mathrm{~g}_{\mathrm{CuO}}{ }^{-1}$ for Cu species ranging from 1 to $20 \mathrm{wt} \%$. c TOF and $E_{\mathrm{a}}$ as function of Cu loading. WHSV $=$ $750,000 \mathrm{~mL}_{\mathrm{CO}} \mathrm{h}^{-1} \mathrm{gCuO}^{-1}$ and $120,000 \mathrm{~mL}_{\mathrm{CO}} \mathrm{h}^{-1} \mathrm{gCuO}^{-1}$ were used below and above $1 \mathrm{wt} \% \mathrm{CuO}$ loading, as indicated in the pink and blue areas, respectively. $\mathbf{d}$ Below $1 \mathrm{wt} \% \mathrm{CuO}$ loading, $\mathrm{CO}$ conversion as a function of $\mathrm{CuO}$ loading amount at $363 \mathrm{~K}$. e Below 1 wt\% CuO loading, CO conversion as a function of the EPR intensity of atomic $\mathrm{Cu}(\mathrm{II})$ site at $363 \mathrm{~K}$. f On stream stability test for $0.20 \mathrm{wt} \% \mathrm{CuO}^{-\mathrm{CeO}_{2}}$ at $1,500,000 \mathrm{~mL}_{\mathrm{CO}} \mathrm{h}^{-1} \mathrm{~g}_{\mathrm{CuO}}{ }^{-1}$ and $413 \mathrm{~K}_{\text {. }}$ $\mathbf{g}$ The correlation of the $\mathrm{CO}$ oxidation TOF of $\mathrm{CuO}-\mathrm{CeO}_{2}$ catalysts against their absorption energies of $1 \mathrm{~s} \rightarrow 3 d$ transition.

catalytic behaviours between atomic $\mathrm{Cu}$ site and oligomers/clusters $^{44}$. In kinetic studies, the ratio between the $\mathrm{CO}$ space velocity and $\mathrm{CuO}$ weight in the bed is fixed. The Arrhenius plots from 0.05 to $1 \mathrm{wt} \%$ loading fall into similar lines with nearly identical slopes (Fig. 3a) while those of catalysts from 1 to $20 \mathrm{wt} \%$ loading show a steady increase in slope (Fig. 3b). As a result, a similar activation energy $\left(E_{\mathrm{a}}\right)$ of $62 \pm 2 \mathrm{~kJ} \mathrm{~mol}^{-1}$ is obtained from 0.05 to $1 \mathrm{wt} \%$ beyond which the $E_{\mathrm{a}}$ increases from 62 to $130 \mathrm{~kJ} \mathrm{~mol}^{-1}$ at $20 \mathrm{wt} \%$ (Fig. 3c). Below $1 \mathrm{wt} \%$, CO conversion has a near linear correlation with $\mathrm{CuO}$ loading and the EPR intensity of atomic $\mathrm{Cu}$ (II) site (Fig. 3d, e; Supplementary Fig. 9). This activityspectroscopy relationship suggests that $\mathrm{CO}$ oxidation is promoted by atomic $\mathrm{Cu}$ site. The similar $E_{\mathrm{a}}$ below $1 \mathrm{wt} \%$ also indicates an atomic site catalytic behaviour, which is in agreement with the EPR quantification (Fig. 2h). The turnover frequency (TOF) at 353,363 and $373 \mathrm{~K}$ as a function of $\mathrm{CuO}$ loading (Fig. 3c) shows similar values below $1 \mathrm{wt} \%$. An average TOF of $0.028 \pm 0.003 \mathrm{~s}^{-1}$ is obtained below $1 \mathrm{wt} \%$ at $373 \mathrm{~K}$ and $0.01 \mathrm{bar}$ $P_{\mathrm{CO}}$. This is kinetic evidence that atomic $\mathrm{Cu}$ site is the main active species as a similar TOF is obtained regardless of $\mathrm{CuO}$ loading. The TOF achieved at $373 \mathrm{~K}$ is comparable with the atomic $\mathrm{Pt}(\mathrm{II})$ site on $\mathrm{CeO}_{2}$ in the literature ${ }^{45}$. Above $1 \mathrm{wt} \%$, the TOF begins to drop and eventually falls below $0.001 \mathrm{~s}^{-1}$ at $353 \mathrm{~K}$ (Fig. 3c). Atomic $\mathrm{Cu}$ site is ten times more active than $\mathrm{CuO}$ clusters in these conditions. The increase of $E_{\mathrm{a}}$ and drop of the TOF above 1 $\mathrm{wt} \%$ is due to the decrease of the atomic site density and formation of $\mathrm{Cu}$ clusters.

The atomic $\mathrm{Cu}(\mathrm{II})$ site are re-examined after catalysis. From 0.1 to $1 \mathrm{wt} \%$, nearly identical EPR spectra are observed, (Supplementary Fig. 10) indicating that the chemical environment of atomic $\mathrm{Cu}(\mathrm{II})$ site stays the same. As a result, high catalytic stability is obtained with a conversion of $18 \%$ for $100 \mathrm{~h}$ (Fig. 3f). For $0.05 \mathrm{wt} \%$, an increase of isolated components $\mathrm{A} 1$ and $\mathrm{C} 1$ is observed. This is associated with the decrease of the long range
(>8 A) coupled component $\mathrm{B} 1$, indicating a redistribution and further isolation of the atomic $\mathrm{Cu}(\mathrm{II})$ site during catalysis (Supplementary Fig. 7b).

The HOMO energy levels, which are consistent with the absorption energies of $1 s \rightarrow 3 d$ transition in the $\mathrm{Cu} \mathrm{K}$ edge XANES, are negatively correlated with TOF in CO oxidation activity (Fig. 3g). The lower HOMO energy level of $\mathrm{Cu}$ single-sites may lead to enhanced competence in $\mathrm{O}_{2}$ activation, which is then investigated via a series of in situ characterisation techniques below.

Dynamics of $\mathrm{O}_{2}$ activation on atomic $\mathrm{Cu}$ site. The difference in catalytic behaviours between atomic $\mathrm{Cu}$ site and $\mathrm{CuO}$ clusters suggests different reaction mechanisms. We hypothesise that this is due to a change in $3 d$ and $4 p$ orbital energy levels in atomic $\mathrm{Cu}$ (II) site (Fig. 2e; Supplementary Fig. 5) caused by the neighbouring $\mathrm{Ce}^{4+}$. This can potentially change the $\mathrm{O}_{2}$ activation pathways during the reaction. NAP-NEXAFS and spin-polarised DFT simulations are performed to investigate the electronic structures of atomic $\mathrm{Cu}(\mathrm{II})$ site upon $\mathrm{O}_{2}$ adsorption. First, the DFT simulation shows that an atomic $\mathrm{Cu}(0)$ site is oxidised to $\mathrm{Cu}$ (I) (calculated effective charge $Q_{\mathrm{Cu}}=0.62|\mathrm{e}|$ at the (111) and $0.48 \mid$ $\mathrm{e} \mid$ at the (110) surface), which coordinates with two lattice oxygen ions to form a $\left[\mathrm{Cu}(\mathrm{I}) \mathrm{O}_{2}\right]^{3-}$ site (Fig. 4a inset, Supplementary Fig. 11a; Supplementary Tables 4 and 5). In the NEXAFS, a $\mathrm{Cu}(\mathrm{I})$ site is identified at the $\mathrm{Cu} \mathrm{L}_{3}$ edge by in situ reduction under $\mathrm{CO}$ at $453 \mathrm{~K}$ with subsequent cooling to $298 \mathrm{~K}$ under ultrahigh vacuum (UHV) (Fig. 4a left) ${ }^{46}$. At the $\mathrm{O}$ K-edge, only the lattice $\mathrm{O}$ of $\mathrm{CeO}_{2}$ is observed (Fig. 4a right; Supplementary Fig. 12).

Upon $\mathrm{O}_{2}$ adsorption at $298 \mathrm{~K}, \mathrm{Cu}(\mathrm{I})$ is partially oxidised to $\mathrm{Cu}$ (II) (Fig. 2b left) while the $\mathrm{O}$ K-edge of gaseous $\mathrm{O}_{2}$ (Fig. 4b right, $530.2 \mathrm{eV}$ ) is clearly different from that of the lattice O (Fig. 4a right, $529.7,532.2$ and $536.7 \mathrm{eV}$ ). UHV is then applied to remove 

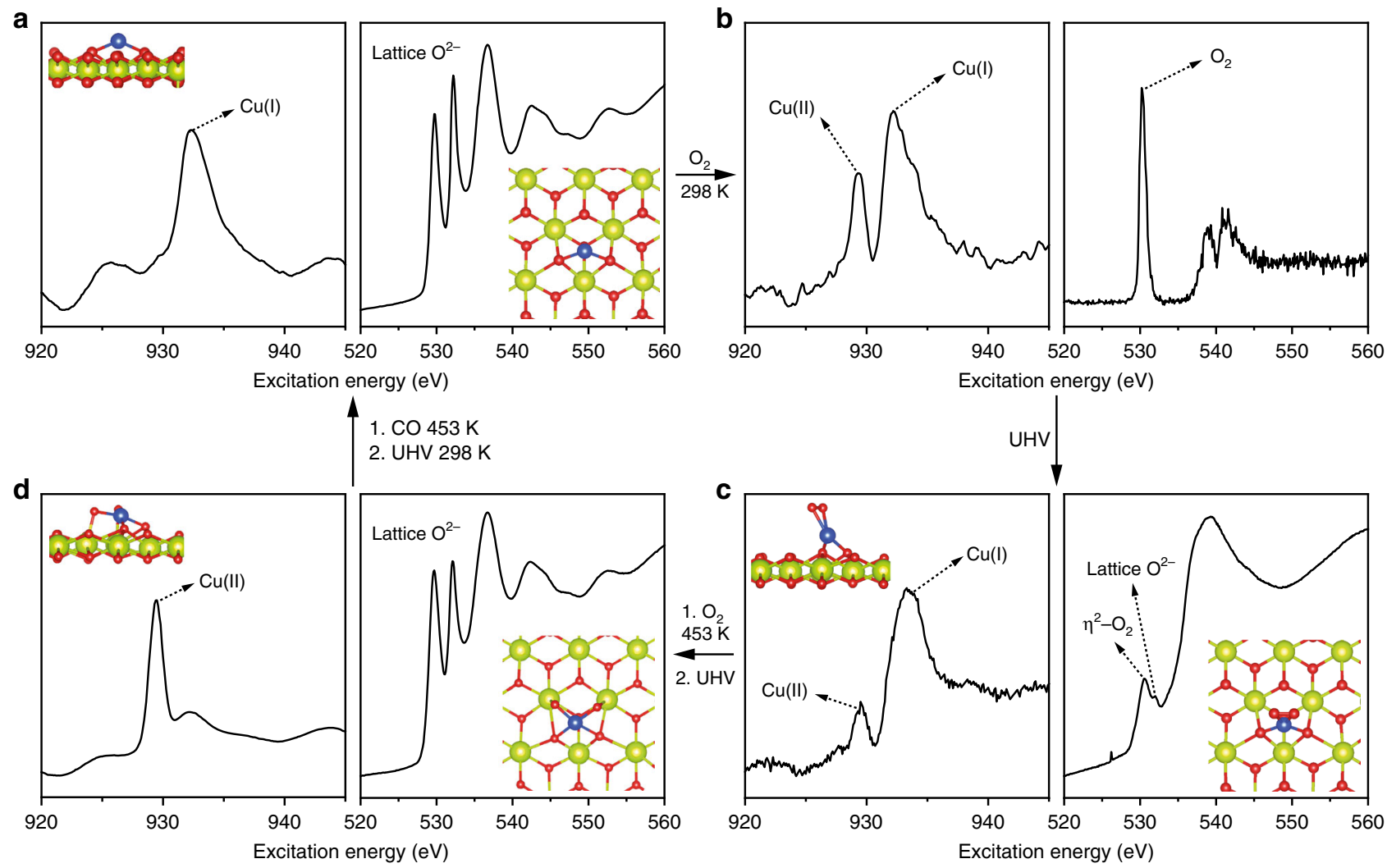

Fig. 4 Activation of $\mathbf{O}_{\mathbf{2}}$ at atomic $\mathbf{C u}$ site. a DFT simulation of an atomic $\mathrm{Cu}(\mathrm{I})$ site over $\mathrm{CeO}_{2}(111)$ surface and NEXAFS of 1 wt\% $\mathrm{CuO}-\mathrm{CeO} 2$ under UHV. The sample is treated with $\mathrm{CO}$ in situ under $453 \mathrm{~K}$ with subsequent cooling to $298 \mathrm{~K}$ under UHV. Left: $\mathrm{Cu} \mathrm{L}_{3}$ edge; Right O K-edge, showing $\mathrm{Cu}(\mathrm{I})$ and lattice O, which is consistent with DFT simulation. $\mathbf{b}$ Upon $\mathrm{O}_{2}$ adsorption at $298 \mathrm{~K}$, the $\mathrm{Cu}_{3}$ edge reveals the formation of $\mathrm{Cu}$ (II) while O K-edge shows surface adsorbed $\mathrm{O}_{2}$. c Under UHV, the gas phase $\mathrm{O}_{2}$ is removed, leaving $\eta^{2}-\mathrm{O}_{2}$ on the surface. The $\mathrm{Cu}$ (II) content is also reduced. d Upon heating to 453 $\mathrm{K}$ under $\mathrm{O}_{2}$ and then changing to $\mathrm{UHV}$, the $\mathrm{Cu}$ is oxidised completely to $\mathrm{Cu}(\mathrm{II})$ while $\eta^{2}-\mathrm{O}_{2}$ is either desorbed or forming lattice $\mathrm{O}^{2-}$.

gas phase $\mathrm{O}_{2}$ and any physically adsorbed $\mathrm{O}_{2}$ at the surface. The $\mathrm{O}$ K-edge NEXAFS shows two absorption peaks at 530.5 and $532.0 \mathrm{eV}$, respectively (Fig. $4 \mathrm{c}$ right). The former is a $\eta^{2}-\mathrm{O}_{2}$ that is adsorbed on atomic $\mathrm{Cu}$ site, while the latter is the lattice $\mathrm{O}$ of $\mathrm{CeO}_{2}$ (Supplementary Fig. 12). In the meantime, the content of $\mathrm{Cu}$ (II) is reduced (Fig. 4c left) ${ }^{47}$. Raman spectroscopy of $1 \mathrm{wt} \%$ $\mathrm{CuO}-\mathrm{CeO}_{2}$ reveals an $\mathrm{O}-\mathrm{O}$ stretch at $830 \mathrm{~cm}^{-1}$, confirming the presence of $\eta^{2}-\mathrm{O}_{2}$ (Supplementary Fig. 13). The shoulder band around $600 \mathrm{~cm}^{-1}$ is attributed to $\mathrm{Ce}^{3+48}$, which is absent for the Raman spectra of $20 \mathrm{wt} \% \mathrm{CuO}-\mathrm{CeO}_{2}$ and pure $\mathrm{CeO}_{2}$. The $20 \mathrm{wt} \%$ $\mathrm{CuO}-\mathrm{CeO}_{2}$, the $\mathrm{CuO}$ standard and the $\mathrm{CeO}_{2}$ standard do not show this $\mathrm{O}-\mathrm{O}$ stretch, suggesting that the $\eta^{2}-\mathrm{O}_{2}$ is associated with atomic $\mathrm{Cu}$ site. DFT simulations show the formation of an electrophilic species $\left[\mathrm{Cu}(\mathrm{II}) \mathrm{O}_{2}\left(\eta^{2}-\mathrm{O}_{2}\right)\right]^{4-}$ upon $\mathrm{O}_{2}$ adsorption (Fig. 4c inset; Supplementary Fig. 11b; Supplementary Tables 4 and 5), which is consistent with the NAP-NEXAFS and Raman results. The $\mathrm{Cu}-\mathrm{O}$ bond lengths match the EXAFS data (Supplementary Tables 1, 4 and 5). The simulated $\mathrm{O}_{2}$ adsorption energy is $-0.68,-1.25$ and $-0.03 \mathrm{eV}$ for an atomic $\mathrm{Cu}$ site over $\mathrm{CeO}_{2}(111)$, an atomic $\mathrm{Cu}$ site over $\mathrm{CeO}_{2}(110)$ and the pure $\mathrm{CeO}_{2}(111)$ surface, respectively, suggesting a strong chemical adsorption at atomic $\mathrm{Cu}$ site. In comparison, $\mathrm{Cu}$ coordinates with four surface lattice $\mathrm{O}^{2-}$ on $\mathrm{CeO}_{2}(100)$ (Supplementary Fig. 14). $\mathrm{O}_{2}$ can only be physically adsorbed on such site with a distance at $3.01 \AA$ based on DFT simulations. Such $\eta^{2}-\mathrm{O}_{2}$ is not observed in the $20 \mathrm{wt} \% \mathrm{CuO}-\mathrm{CeO}_{2}$ (Supplementary Fig. 15).

Upon heating to $453 \mathrm{~K}$ under $\mathrm{O}_{2}$ with subsequent UHV, only lattice $\mathrm{O}$ is visible in the $\mathrm{O} \mathrm{K}$-edge NAP-NEXAFS, while almost all the $\mathrm{Cu}$ is oxidised to $\mathrm{Cu}$ (II) (Fig. $4 \mathrm{~d})^{46}$. The DFT simulations also indicate the cleavage of the $\mathrm{O}-\mathrm{O}$ bond, forming a $[\mathrm{Cu}(\mathrm{II})$
$\left.\mathrm{O}_{4}\right]^{6-}$ site (Fig. 4d inset; Supplementary Fig. 11c). The calculated charge per $\mathrm{O}_{\text {ads }}$ atom decreases from -0.22 to -0.595 (Supplementary Table 8). The calculated barrier from $\left[\mathrm{Cu}(\mathrm{II}) \mathrm{O}_{2}\left(\eta^{2}-\mathrm{O}_{2}\right)\right]^{4-}$ to $\left[\mathrm{Cu}(\mathrm{II}) \mathrm{O}_{4}\right]^{6-}$ is $1.41 \mathrm{eV}$ (Supplementary Fig. 16). In comparison, decomposition of $\mathrm{O}_{2}$ on $\mathrm{Cu}_{2} \mathrm{O}(111)$ surface requires an energy barrier of $1.13 \mathrm{eV}$ (Supplementary Fig. 17). The final state with fully dissociated $\mathrm{O}$ atoms is $0.3 \mathrm{eV}$ more stable than the initial undissociated $\mathrm{O}_{2}$, whereas the final state of oxygen on $\mathrm{Cu}$ single site is $1.05 \mathrm{eV}$ less stable than its initial state. These results suggest the dissociation of $\mathrm{O}_{2}$ on $\mathrm{Cu}_{2} \mathrm{O}$ clusters is easier than that on $\mathrm{Cu}$ single sites. The $[\mathrm{Cu}(\mathrm{II})$ $\left.\mathrm{O}_{4}\right]^{6-}$ can be further converted back to $\left[\mathrm{Cu}(\mathrm{II}) \mathrm{O}_{2}\left(\eta^{2}-\mathrm{O}_{2}\right)\right]^{4-}$ by just reducing the temperature to $298 \mathrm{~K}$, suggesting the reversible conversion between these two $\mathrm{Cu}(\mathrm{II})$ sites (Supplementary Fig. 18). In the last step, $\mathrm{CO}$ reduces $\left[\mathrm{Cu}(\mathrm{II}) \mathrm{O}_{4}\right]^{6-}$ at $453 \mathrm{~K}$, to resume the original $\left[\mathrm{Cu}(\mathrm{I}) \mathrm{O}_{2}\right]^{3-}$. Bader charge analysis is calculated to analyse the charge transfer between $\mathrm{Cu}(\mathrm{I} / \mathrm{II})$ sites and $\mathrm{Ce}^{4+}$ on the $\mathrm{CeO}_{2}(111)$ surface. In both $\left[\mathrm{Cu}(\mathrm{I}) \mathrm{O}_{2}\right]^{3-}$ and $\left[\mathrm{Cu}(\mathrm{II}) \mathrm{O}_{4}\right]^{6-}$ sites, a charge transfer from $\mathrm{Cu}$ at the value of +0.617 and +1.074 is observed, respectively. Ce receives charge at the value of -0.524 and -0.316 for $27 \mathrm{Ce}^{4+}$ ions that participate in the calculation, respectively (Supplementary Figs. 19 and 20; Supplementary Tables 6-8). Based on the same calculations parameters for the $\mathrm{Cu}$ single-sites, the calculated Bader charges of $\mathrm{Cu}_{2} \mathrm{O}(111)$ and $\mathrm{CuO}(111)$ surface are +0.495 and +1.001 , respectively (Supplementary Table 9). Compared with pure copper oxides, both $\mathrm{Cu}(\mathrm{I})$ and $\mathrm{Cu}(\mathrm{II})$ single sites on $\mathrm{CeO}_{2}$ are more positively charged. The increase of electron density of $\mathrm{Ce}$ in both models proves the role of $\mathrm{Ce}^{4+}$ as an electron acceptor for the atomic $\mathrm{Cu}(\mathrm{I} / \mathrm{II})$ sites. 
The $\mathrm{O}_{2}$ activation over $\left[\mathrm{Cu}(\mathrm{I}) \mathrm{O}_{2}\right]^{3-}$ site can be understood by $\left[\mathrm{Cu}(\mathrm{I}) \mathrm{O}_{2}\right]^{3-}+\mathrm{O}_{2}+\mathrm{Ce}^{3+} \rightarrow\left[\mathrm{Cu}(\mathrm{II}) \mathrm{O}_{2}\left(\eta^{2}-\mathrm{O}_{2}\right)\right]^{4-}+\mathrm{Ce}^{4+}$

(Fig. 4a-c; Supplementary Fig. 21). One $\mathrm{Ce}^{3+}$ is required to donate one electron form the $\eta^{2}-\mathrm{O}_{2}$ species. During heating at $453 \mathrm{~K}, \eta^{2}-\mathrm{O}_{2}$ is formally reduced via $\left[\mathrm{Cu}(\mathrm{II}) \mathrm{O}_{2}\left(\eta^{2}-\mathrm{O}_{2}\right)\right]^{4-}+$ $2 \mathrm{Ce}^{3+} \rightarrow\left[\mathrm{Cu}(\mathrm{II}) \mathrm{O}_{4}\right]^{6-}+2 \mathrm{Ce}^{4+}$ (Fig. $4 \mathrm{c}-\mathrm{d}$ ). We hypothesise that another two $\mathrm{Ce}^{3+}$ are required to balance the charges. Finally, during $\mathrm{CO}$ oxidation, $\left[\mathrm{Cu}(\mathrm{II}) \mathrm{O}_{4}\right]^{6-}+2 \mathrm{CO}+3 \mathrm{Ce}^{3+} \rightarrow[\mathrm{Cu}(\mathrm{I})$ $\left.\mathrm{O}_{2}\right]^{3-}+2 \mathrm{CO}_{2}+3 \mathrm{Ce}^{4+}$. Only a small amount of Ce participates the reaction for $1 \mathrm{wt} \% \mathrm{CuO}-\mathrm{CeO}_{2}$ catalysts, which is then difficult to detect via in situ spectroscopy. In addition to $\mathrm{O}_{2}$, activation of $\mathrm{CO}$ and the mobility of lattice $\mathrm{O}$ in $\mathrm{CeO}_{2}$ are also important for the $\mathrm{CO}$ oxidation. $\mathrm{CO}$ temperature programmed reduction and desorption are performed to compare the activation of $\mathrm{CO}$ with $\mathrm{Cu}$ single-site and clusters. The atomic $\mathrm{Cu}(\mathrm{II})$ sites are more active towards $\mathrm{CO}$ adsorption and oxidation than the majority of $\mathrm{CuO}$ sites on clusters as reflected by the shift of the reduction peak from 451 to $380 \mathrm{~K}$ (Supplementary Fig. 22a). The $\mathrm{Cu}(\mathrm{II})$ site shows the main desorption peak at $374 \mathrm{~K}$, which is $6 \mathrm{~K}$ lower than that of the $\mathrm{CuO}$ clusters (Supplementary Fig. 22b). Higher $\mathrm{Ce}^{3+}$ content $^{49}$ is found in the $1 \mathrm{wt} \% \mathrm{CuO}-\mathrm{CeO}_{2}$ comparing with $20 \mathrm{wt} \% \mathrm{CuO}-\mathrm{CeO}_{2}$ (Supplementary Fig. 23; Supplementary Table 10), which agrees with the shoulder band at $600 \mathrm{~cm}^{-1}$ in the Raman spectrum (Supplementary Fig. 13). According to the MvK mechanism, high $\mathrm{Ce}^{3+}$ content suggests more oxygen vacancy formation ${ }^{50}$, and thus improve the mobility of lattice $\mathrm{O}^{51}$. Therefore, the presence of the atomic $\mathrm{Cu}$ site promotes the $\mathrm{O}_{2}$ and $\mathrm{CO}$ activation and the lattice $\mathrm{O}$ mobility, leading to higher $\mathrm{CO}$ oxidation activity compared with $\mathrm{CuO}$ clusters (Fig. 3c).

The role of $\mathbf{C u}(\mathrm{I} / \mathrm{II})$ single-sites in $\mathrm{CO}$ oxidation. The NAP surface experiments and DFT simulations identify the presence and transformation of $\left[\mathrm{Cu}(\mathrm{I}) \mathrm{O}_{2}\right]^{3-},\left[\mathrm{Cu}(\mathrm{II}) \mathrm{O}_{2}\left(\eta^{2}-\mathrm{O}_{2}\right)\right]^{4-}$ and $\left[\mathrm{Cu}(\mathrm{II}) \mathrm{O}_{4}\right]^{6-}$ sites at low pressure. We hypothesise that they are the intermediate states under the $\mathrm{CO}$ oxidation conditions. We first aim to identify the $\left[\mathrm{Cu}(\mathrm{I}) \mathrm{O}_{2}\right]^{3-}$ during the reaction under a reductive atmosphere.

The XAFS (Fig. 5a-c)/EPR (Fig. 5d) spectra and outlet concentration of $\mathrm{CO}, \mathrm{CO}_{2}$ and $\mathrm{O}_{2}$ are recorded simultaneously. Under air and $\mathrm{N}_{2}$, EPR observes a low content of a well-defined isolated $\mathrm{Cu}$ (II) $\left(g_{\|}=2.275, g_{\perp}=2.050, A_{\|}=492 \mathrm{MHz}, A_{\perp}=34\right.$ $\mathrm{MHz}$; signal C2 in Supplementary Fig. 8) that is highly sensitive to oxygen. Supplying 2\% CO lowers the dominant EPR signal of atomic $\mathrm{Cu}(\mathrm{II})$ site, suggesting a reduction of $\mathrm{Cu}(\mathrm{II})$ (Fig. $5 \mathrm{~d}$ ). Simulations of the difference between EPR spectra recorded under CO and under air (signal B2 in Supplementary Fig. 8), indicate that the $\mathrm{Cu}(\mathrm{II})$ species coordination is of rhombic symmetry $\left(g_{\mathrm{z}}=2.28, g_{\mathrm{y}}=2.132, g_{\mathrm{x}}=2.051, A_{\mathrm{z}}=472 \mathrm{MHz}, A_{\mathrm{x}, \mathrm{y}}\right.$ $=35 \mathrm{MHz}$ ) and compatible with a tetrahedral distorted squareplanar ligand sphere. The corresponding XANES spectra show that the reduction reached and maintained $\mathrm{Cu}(\mathrm{I})$ without further reduction to $\mathrm{Cu}(0)$ (Fig. 5b). No $\mathrm{Cu}-\mathrm{Cu}$ scattering is found in the EXAFS, suggesting a stable atomic $\mathrm{Cu}(\mathrm{I})$ site species rather than $\mathrm{Cu}_{2} \mathrm{O}$ clusters. The EXAFS spectra are fitted with a corrected Debye-Waller factor for the temperature of the reaction (Supplementary Fig. 24). The coordination number of $\mathrm{Cu}-\mathrm{O}$ decreases from $3.93 \pm 0.18$ to $2.03 \pm 0.11$, while the bond distance is maintained at $1.90 \pm 0.01 \AA$ (Fig. 5c; Supplementary Figs. 25 and 26; Supplementary Table 11). The $\mathrm{Cu}-\mathrm{O}$ bond distance agrees well with the DFT model of the $\left[\mathrm{Cu}(\mathrm{I}) \mathrm{O}_{2}\right]^{3-}$ site on $\mathrm{CeO}_{2}$ surface (Supplementary Tables 4 and 5). As the $\mathrm{Cu}-\mathrm{O}$ bond is not elongated to match the $\mathrm{Ce}-\mathrm{O}$ bond length $(2.38 \AA)$ in bulk $\mathrm{CeO}_{2}{ }^{52}$, such atomic $\mathrm{Cu}$ sites are not likely to be stabilised by substituting $\mathrm{Ce}$ atoms in $\mathrm{CeO}_{2}$ lattice.
The $\left[\mathrm{Cu}(\mathrm{I}) \mathrm{O}_{2}\right]^{3-}$ is stable under a reductive atmosphere, corroborating the DFT simulations in which a $\mathrm{Cu}(0)$ atom is immediately oxidised to $\mathrm{Cu}(\mathrm{I})$ by $\mathrm{Ce}^{4+}$ at the $\mathrm{CeO}_{2}(111)$ surface (Fig. 4a; Supplementary Fig. 27). In comparison with CO atmosphere, atomic $\mathrm{Cu}(\mathrm{II})$ site is stable under $\mathrm{H}_{2}$ at $453 \mathrm{~K}$ (Supplementary Fig. 28), due to the lack of a metallic surface for the dissociation of $\mathrm{H}-\mathrm{H}$ bond. XANES of $1 \mathrm{wt} \% \mathrm{CuO}-\mathrm{CeO}_{2}$ shows weaker absorption from $1 s \rightarrow 4 p$ transition than that of 20 wt $\%$ and bulk $\mathrm{Cu}_{2} \mathrm{O}$ (Supplementary Fig. 29). The absorption energy of $1 s \rightarrow 4 p$ transitions increases from $8980.6 \mathrm{eV}$ for bulk $\mathrm{Cu}_{2} \mathrm{O}$ and $\mathrm{Cu}_{2} \mathrm{O}$ clusters at $20 \mathrm{wt} \%$ to $8980.9 \mathrm{eV}$ for $\left[\mathrm{Cu}(\mathrm{I}) \mathrm{O}_{2}\right]^{3-}$ at $1 \mathrm{wt} \%$, respectively, indicating an increase of the $4 p$ orbital energy level relative to the $1 s$ orbital for $\left[\mathrm{Cu}(\mathrm{I}) \mathrm{O}_{2}\right]^{3-}$ site. DFT calculation shows that the $\mathrm{Cu}(\mathrm{I})$ single-site on $\mathrm{CeO}_{2}(111)$ has significantly lower valence band maximum compared with $\mathrm{Cu}_{2} \mathrm{O}$ (111) surface $(-0.9451 \mathrm{eV}$ vs. $-0.2244 \mathrm{eV}$, Supplementary Table 12). Such a $0.7207 \mathrm{eV}$ difference from calculations of $\mathrm{Cu}$ (I) species is very close to that of the experimentally measured difference in $1 s \rightarrow 3 d$ transition energy of $\mathrm{Cu}(\mathrm{II})$ species $(0.6 \mathrm{eV}$, Fig. 2e). This result further validates that both $\mathrm{Cu}(\mathrm{I})$ and $\mathrm{Cu}(\mathrm{II})$ single-sites on $\mathrm{CeO}_{2}$ have lower HOMO energy compared with $\mathrm{Cu}$ clusters.

Ultrapure $\mathrm{N}_{2}$ was introduced to remove the reducing CO. A slow increase in paramagnetic $\mathrm{Cu}(\mathrm{II})$ is observed in the EPR (Fig. 5d; Supplementary Fig. 8) and XANES (Fig. 5b), suggesting oxidation of $\mathrm{Cu}(\mathrm{I})$ by $\mathrm{Ce}^{4+53}$. As a result, increased coordination numbers of in $\mathrm{Cu}-\mathrm{O}, \mathrm{Cu}-\mathrm{Ce}(1)$ and $\mathrm{Cu}-\mathrm{Ce}(2)$ from $2.03 \pm 0.11$, $1.46 \pm 1.16$ and $0.70 \pm 0.46$ to $3.62 \pm 0.18,2.91 \pm 1.29$ and $1.94 \pm$ 0.82 are found (Fig. 5c, Supplementary Figs. 25 and 26; Supplementary Table 11).

The CO oxidation is carried out at CO: $\mathrm{O}_{2}$ ratios of 1:1, 2:1 and $4: 1$, respectively. From the oxidative reaction condition at $1: 1$ to the reductive condition at $4: 1$, a reduction of $\mathrm{Cu}(\mathrm{II})$ to $\left[\mathrm{Cu}(\mathrm{I}) \mathrm{O}_{2}\right]^{3-}$ is found and associated with the decrease of coordination numbers of $\mathrm{Cu}-\mathrm{O}, \mathrm{Cu}-\mathrm{Ce}(1)$ and $\mathrm{Cu}-\mathrm{Ce}(2)$ (Fig. 5b, c). Such a structural evolution of atomic $\mathrm{Cu}$ site under different reaction environments has also been reported for the $\mathrm{Pt}$ site system recently ${ }^{54}$. The comparison among the TOFs obtained with various $\mathrm{Cu}$-based and Pt-based catalysts in $\mathrm{CO}$ oxidation shows that the atomic $\mathrm{Cu}$ sites in $1 \mathrm{wt} \% \mathrm{CuO}-\mathrm{CeO}_{2}$ is more active than the reported $\mathrm{Cu}$ clusters catalysts and the activity is comparable with that of the isolated Pt sites on $\mathrm{CeO}_{2}{ }^{45}$ (Supplementary Table 13; Supplementary Note 2).

To summarise the operando study and DFT simulations, a stable $\left[\mathrm{Cu}(\mathrm{I}) \mathrm{O}_{2}\right]^{3-}$ site has been identified under reductive conditions. The $4 p$ orbital energy level relative to that of the $1 \mathrm{~s}$ orbital increases from bulk $\mathrm{Cu}_{2} \mathrm{O}$, via $\mathrm{Cu}_{2} \mathrm{O}$ clusters to the $[\mathrm{Cu}(\mathrm{I})$ $\left.\mathrm{O}_{2}\right]^{3-}$ site, which proves the hypothesis that an atomic site has higher unoccupied orbital energy than the clusters and bulk materials (Fig. 1). In addition, a dynamic change of structure between $\left[\mathrm{Cu}(\mathrm{I}) \mathrm{O}_{2}\right]^{3-}$ and $\left[\mathrm{Cu}(\mathrm{II}) \mathrm{O}_{2}\left(\eta^{2}-\mathrm{O}_{2}\right)\right]^{4-} /\left[\mathrm{Cu}(\mathrm{II}) \mathrm{O}_{4}\right]^{6-}$ species has been found under $\mathrm{CO}$ rich and lean conditions.

\section{Discussion}

In this work, we hypothesise and demonstrate the concept of using electronic structures to control catalytic activity. With the HOMO lower in energy, the atomic $\mathrm{Cu}$ site shows a ten times higher activity to that of $\mathrm{CuO}$ clusters with only half of the Ea. An electrophilic $\left[\mathrm{Cu}(\mathrm{II}) \mathrm{O}_{2}\left(\eta^{2}-\mathrm{O}_{2}\right)\right]^{4-}$ species is obtained upon adsorption of molecular $\mathrm{O}_{2}$, which is the key intermediate state between reduced $\left[\mathrm{Cu}(\mathrm{I}) \mathrm{O}_{2}\right]^{3-}$ site and oxidised $\left[\mathrm{Cu}(\mathrm{II}) \mathrm{O}_{4}\right]^{6-}$ site. Such dynamics are revealed by a combination of ex situ XPS, in situ Soft X-rays (NEXAFS), hard X-rays (XAS), and EPR techniques supported by DFT simulations. The rarely reported $\left[\mathrm{Cu}(\mathrm{II}) \mathrm{O}_{2}\left(\eta^{2}-\mathrm{O}_{2}\right)\right]^{4-}$ site has high potential for selective 

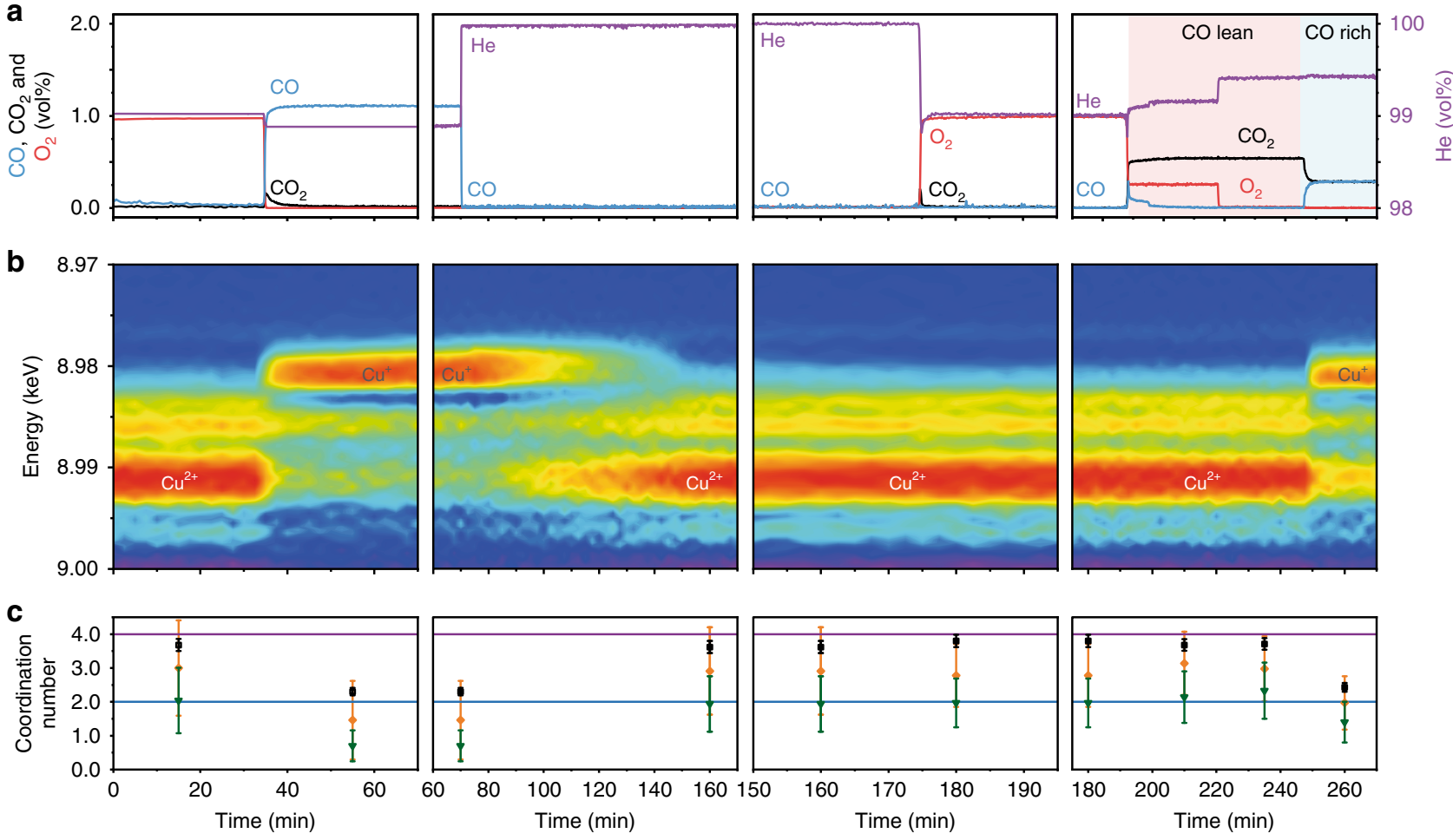

$\mathrm{Cu}-\mathrm{O}$ in $\mathrm{CuO}(\mathrm{C} . \mathrm{N} .=4.0, d=1.95 \AA)$

$\mathrm{Cu}-\mathrm{O}$ in $\mathrm{Cu}_{2} \mathrm{O}(\mathrm{C} . \mathrm{N} .=2.0, d=1.85 \AA$ )

- $\mathrm{Cu}-\mathrm{O}$
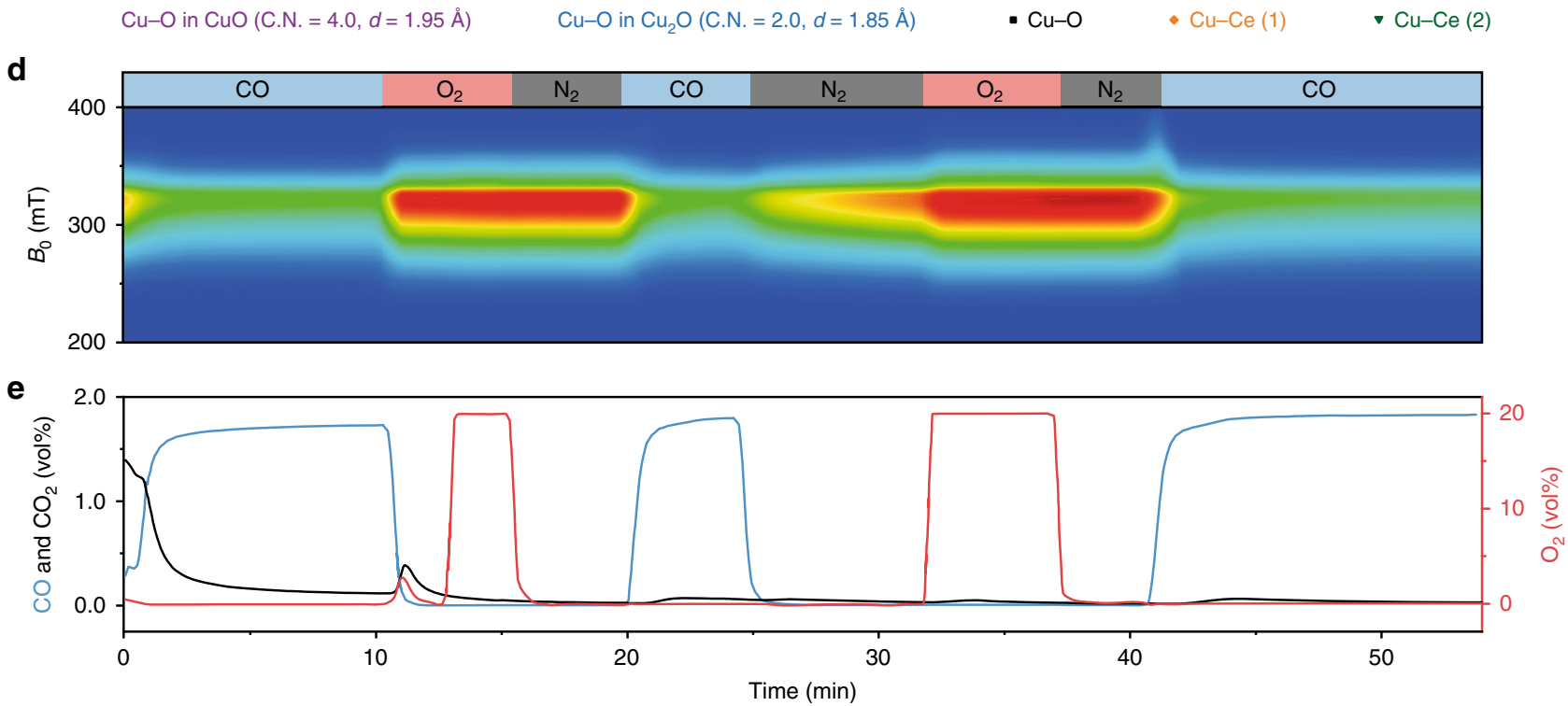

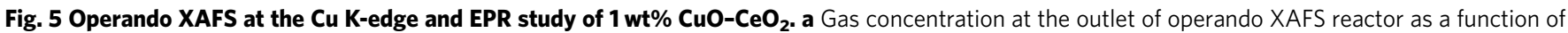
time. $\mathbf{b}$ Contour map of the first derivative XANES spectra, showing the continuous changes of absorption edge fine structure. $\mathbf{c}$ Corresponding change of coordination number in $\mathrm{Cu}-\mathrm{O}, \mathrm{Cu}-\mathrm{Ce}$ (1) and $\mathrm{Cu}-\mathrm{Ce}$ (2) scattering as a function of time. $\mathbf{d}$ Contour map of the first integral of EPR intensity of atomic $\mathrm{Cu}$ (II) site as a function of time. e The corresponding gas concentrations.

oxidation reactions such as epoxidation and $\mathrm{C}-\mathrm{H}$ activation. The ability to precisely design and control electronic structures of atomically dispersed active sites will be the key to selective chemical transformations, validated by the modified HOMO of this atomic $\mathrm{Cu}$ catalyst. Moreover, we provide a general strategy to use the interaction between atomic metal and supporting cations to achieve this goal, which could be extended to other supported catalysts.

\section{Methods}

Catalysts preparation. The $\mathrm{CuO}-\mathrm{CeO}_{2}$ composites were synthesised by the flame spray pyrolysis (FSP) method. The copper and cerium precursor solutions with different $\mathrm{Cu}: \mathrm{Ce}$ ratios were prepared by mixing appropriate amounts of cerium acetylacetonate (Sigma-Aldrich) with copper 2-ethylhexanoate (Sigma-Aldrich) in a solution of acetic acid (Fluka, $>98.5 \%$ ), methanol (Sigma-Aldrich, 99.9\%), and xylene (Sigma-Aldrich, 95\%) (25 vol\% acetic acid, $25 \mathrm{vol} \%$ methanol, and $50 \mathrm{vol} \%$ xylene, volume ratio $1: 1: 2$ ). The resulting total metal concentration was $0.1 \mathrm{~mol} / \mathrm{L}$ These precursor solutions were sprayed at $2 \mathrm{~mL} / \mathrm{min}$, dispersed with $8 \mathrm{~L} / \mathrm{min} \mathrm{O}_{2}$ (Pangas, 99,95\%), and ignited by a premixed $\mathrm{CH}_{4} / \mathrm{O}_{2}$ ring-shaped flamelet (flow rates 1 and $2 \mathrm{~L} / \mathrm{min}$, respectively). The resulting flame-made materials were collected from the filter and were not subject to additional temperature treatment. $\mathrm{CuO}-\mathrm{CeO}_{2}$ materials with $\mathrm{CuO}$ contents of $0,0.05,0.1,0.2,0.4,0.8,1,2,3,4,5,10$, 15 and $20 \mathrm{wt} \%$ (based on the weight percentage of $\mathrm{CuO}$ in the whole materials) were made by tailoring the ratio between copper 2-ethylhexanoate and cerium acetylacetonate.

Transmission electron microscopy (TEM) investigations. Samples were prepared by sprinkling a small amount of dry sample powder on 300 mesh copper 
grids with formvar carbon supported film. TEM images were acquired on JEM 2100 (JEOL, Japan) operated at $200 \mathrm{kV}$ acceleration voltage. The average particle size of $\mathrm{CuO}-\mathrm{CeO}_{2}$ composites was calculated based on more than 100 particles for each sample.

HAADF-STEM investigations. Samples were prepared by sprinkling a small amount of dry sample powder on 400 mesh gold grids with lacey carbon support film. High resolution aberration-corrected HAADF-STEM images were either obtained from the probe-corrected (CEOS) JEM ARM 200CF (JEOL, Japan) operated at $200 \mathrm{keV}$ or the probe-corrected (JEOL-COSMO) JEM ARM 300CF (JEOL, Japan) operated at $300 \mathrm{keV}$. We used a $40 \mu \mathrm{m}$ probe-forming aperture, resulting in $31.8 \mathrm{mrad}$ probe convergence semi-angle. The HAADF signal was gathered at $2.5 \mathrm{~cm}$ STEM camera length, integrating the scattered electron intensity between 100 and $170 \mathrm{mrad}$. In order to mitigate the accumulation of carbon contamination during STEM imaging, the regions of interest were exposed to an intense electron "beam shower" for $15 \mathrm{~min}$.

EDS investigations. Data were obtained from the probe-corrected JEM ARM 200CF (JEOL, Japan) with large solid-angle dual EDS detectors for X-ray spectroscopy and elemental mapping. The EDS data acquisition was carried out in STEM imaging mode, with a probe current of $143 \mathrm{pA}$ (probe size is 5 C) at $200 \mathrm{keV}$ acceleration voltage. Each EDS spectrum image is $55 \times 55$ pixels in size, with $0.05 \mathrm{~s}$ exposure time per pixel. To improve the signal-noise ratio, the mapping procedure for each region was performed four times with special drifting correction before the mappings were merged. Gatan Microscopy Suite Software was used for EDS spectrum imaging data acquisition.

XANES and EXAFS investigations. The analysis of the $\mathrm{Cu}$ K-edge $(8.979 \mathrm{keV})$ was performed at $3.0 \mathrm{GeV}$ with a beam current of $300 \mathrm{~mA}$ at the Beamline B18 of the Diamond Light Source (UK) ${ }^{55,56}$. A QEXAFS mode was set-up through a fastscanning $\mathrm{Si}(111)$ double crystal monochromator, and Pt-coated branch of collimating and focus mirrors. A couple of Pt-coated harmonic rejection mirrors were inserted between the monochromator and ion chamber to cut off the photons with higher energy. The photon flux at $8 \mathrm{keV}$ (near $\mathrm{Cu} \mathrm{K}$-edge at $8.797 \mathrm{keV}$ ) was $5 \times$ $10^{11} \mathrm{ph} / \mathrm{s}$ with a beam size of $200(\mathrm{H}) \times 250(\mathrm{~V}) \mu \mathrm{m}$. The time resolution of the spectra was $2.5 \mathrm{~min} / \mathrm{spectrum}\left(k_{\max }=17\right.$, step size $\left.0.3 \mathrm{eV}\right)$. The XAFS spectra of all samples were measured in an energy range of $8780-10150 \mathrm{keV}$.

HERFD-XANES investigations. The measurements were performed at the I20Scanning beamline at Diamond Light Source $(\mathrm{UK})^{57,58}$. X-ray beam was introduced via Rh coated optic hutch mirrors and Si(111) scanning four bounce monochromators for selecting incident energy ${ }^{59}$. The HERFD-XANES spectra were acquired by scanning the incident energy from 8800.00 to $9400.00 \mathrm{eV}$ with $0.15 \mathrm{eV}$ resolution and monitoring the intensity of the $\mathrm{Cu} \mathrm{K} \beta_{1,3}$ line $(8905.30 \mathrm{eV})$ by three $100 \mathrm{~mm} \mathrm{Si}(642)$ spherical crystal analyser. $\mathrm{Cu}_{2} \mathrm{O}, \mathrm{CuO}, 1 \mathrm{wt} \% \mathrm{CuO}-\mathrm{CeO}_{2}$ and $20 \mathrm{wt} \% \mathrm{CuO}-\mathrm{CeO}_{2}$ were diluted with boron nitride and pressed into a pellet $(d=13 \mathrm{~mm})$ for measurement. The XANES analysis was conducted with Demeter software package ${ }^{60}$.

Ex situ XAFS measurements were performed in transmission mode using ion chamber detectors (for samples loading more than $5 \mathrm{wt} \% \mathrm{CuO}$ ) and fluorescence mode using 36-element Ge solid-state detector system (for samples loading less than $5 \mathrm{wt} \% \mathrm{CuO}$ ). Cu foil standard was used for energy shift calibration. $\mathrm{CuO}$, $\mathrm{Cu}_{2} \mathrm{O}$ standards and $\mathrm{CuO}-\mathrm{CeO}_{2}$ samples $(>5 \mathrm{wt} \%$ loading) were diluted with cellulose and pressed into a $0.8 \mathrm{~mm}$ diameter pellets for transmission measurement. $\mathrm{CuO}-\mathrm{CeO}_{2}$ samples ( $<5 \mathrm{wt} \%$ loading) were directly pressed into pellets for fluorescence measurement. In order to improve the signal-noise ratio the spectrum of each sample was measured 3 times for transmission mode and 10-60 times for fluorescence mode.

Operando XANES and EXAFS investigations. The measurements of $\mathrm{CuO}-\mathrm{CeO}_{2}$ catalysts were performed in a plug-flow microreactor with the same X-ray beam setup and data acquisition parameters. The catalysts powder was packed into a Kapton foil reaction tube (diameter $6 \mathrm{~mm}$ ) with quartz wool at both ends. The reaction tube was connected to the gas supply system. A K-type thermal couple was inserted into the catalysts bed to monitor the temperature. A hot air gun was placed under the reaction tube to heat the catalysts bed (heating and cooling ramp rate of $10{ }^{\circ} \mathrm{C} \mathrm{min}-1$ and $20^{\circ} \mathrm{C} \mathrm{min}^{-1}$, respectively). The heating zone was sheathed with an additional ceramic drivepipe to improve the heat conductivity and prevent uneven heating. Two $3 \mathrm{~mm} \times 15 \mathrm{~mm}$ windows were placed on both sides of the ceramic drivepipe to let $\mathrm{X}$-rays passing through.

Totally, 1,5 and $20 \mathrm{wt} \% \mathrm{CuO}-\mathrm{CeO}_{2}$ sample powders were measured in fluorescence mode. Boron nitride was used to dilute the $20 \mathrm{wt} \%$ sample to minimise the self-absorption effect. During the reaction, XAFS spectra were acquired every 150 s continuously.

$\mathrm{CO}$ oxidation reaction was carried out under $1-5 \mathrm{vol} \% \mathrm{CO} / \mathrm{He}$ and $1-5 \mathrm{vol} \% \mathrm{O}_{2} /$ He over approximately $10 \mathrm{mg}$ of the catalysts (WHSV $=6 \times 10^{5} \mathrm{~mL}_{\mathrm{CO}} \mathrm{g}_{\mathrm{CuO}}{ }^{-1} \mathrm{~h}^{-1}$ ). Outlet gases were sampled continuously with the Quadrupole Mass Spectrometer Quantitative Gas Analyser (Hiden Analytical, UK). The Hiden QGA can continuously sample and scan atomic mass range from 1 to $200 \mathrm{AMU}$ with
500 times/s for measurement speed. The analysis sensitivity is $100 \%$ to $100 \mathrm{PPB}$ subject to spectral interference. The gas profile was simulated and analysed by automatic subtraction of spectral overlaps.

XAFS data were analysed by Demeter software package (including Athena and Artemis, version 0.9 .25$)^{60}$. Athena software was used for data extraction and XANES analysis. Artemis software was used to fit the $k^{3}$-weighted EXAFS data $\left(3.0 \AA^{-1}<k<12.5 \AA^{-1}\right)$ with $1.0 \AA<R<4.0 \AA(0.05-5 \mathrm{wt} \%)$ or $1.0 \AA<R<3.0 \AA$ (5-20 wt\%). The calculated amplitude reduction factor $\mathrm{S}_{0}{ }^{2}$ from EXAFS analysis of $\mathrm{Cu}$ foil was 0.809 , which was used as a fixed parameter for EXAFS fitting. The increase of the Debye-Waller factor $\sigma^{2}$, indicating the relative displacement of absorber and backscatter atoms, was calculated based on a linear fitting of $\sigma^{2}$ value as a function of temperature. The same changing rate (slope) of $\sigma^{2}$ value was applied to the spectra collected during the $\mathrm{CO}$ oxidation experiment while the initial $\sigma^{2}$ value was determined by the fitting of the spectra collected at room temperature.

X-band EPR investigations. The experiments were performed in continuous-wave (cw) mode on a Bruker E580 X-band EPR spectrometer equipped with a Bruker ER4122-SHQE cavity. Totally, $20 \mathrm{mg}$ powder of each sample was loaded into a high purity quartz EPR tube ( $4.0 \mathrm{~mm}$ o.d., $3.0 \mathrm{~mm}$ i.d.) for measurement. All the $\mathrm{cw}$ EPR spectra were acquired at room temperature over a wide magnetic field range. Typical spectrometer parameters were: sweep time $(300 \mathrm{~s})$, centre field $(300 \mathrm{mT})$, sweep width $(300 \mathrm{mT})$, modulation frequency $(100 \mathrm{kHz})$, microwave frequency $(9.87 \mathrm{GHz})$, microwave power $(2.0 \mathrm{~mW})$. Operando EPR spectra were recorded using a fixed-bed continues-flow reactor setup ${ }^{53}$ inserted in the EPR cavity with $\sim 80 \mathrm{mg}$ of the powder catalyst exposed to the flow of reactive/inert gases with WHSV of $60,000 \mathrm{~mL} \mathrm{~h}^{-1} \mathrm{~g}^{-1}$ at $393 \mathrm{~K}$. Typical spectrometer parameters were: sweep time $(160 \mathrm{~s})$, centre field $(270 \mathrm{mT})$, sweep width $(320 \mathrm{mT})$, modulation frequency $(100 \mathrm{kHz})$, microwave frequency $(9.32 \mathrm{GHz})$ and microwave power $(20.0 \mathrm{~mW})$. The EPR spectra were simulated and analysed using the Easyspin ${ }^{61}$ toolbox running in MATLAB.

XRD investigations. The measurement was performed on Bruker D8 diffractometer with a voltage of $40 \mathrm{kV}$ at $30 \mathrm{~mA}$, using a Cu source with $K_{\alpha 1}=$ $1.540562 \AA$ and $K_{\alpha 2}=1.544398 \AA$. The contributions of $K_{\alpha 2}$ line in the XRD patterns were subtracted.

SXPD investigations. The measurement of $\mathrm{CuO}-\mathrm{CeO}_{2}$ catalysts was carried out at Beamline I11 in Diamond Light Source (UK) ${ }^{62}$. A monochromatic beam with calibrated wavelength at 0.826115 (10) $\AA$ from Si (SRM640c) standard was used to obtain X-ray diffraction patterns (from $2 \theta=2-92^{\circ}$ with $0.004^{\circ}$ step size). The powder patterns were obtained using the fast position sensitive detector ${ }^{63}$.

Nitrogen adsorption investigations. The adsorption-desorption isotherms were recorded at $77 \mathrm{~K}$ using a Micromeritics 3Flex surface characterisation analyser. The samples were degassed in vacuum at $200{ }^{\circ} \mathrm{C}$ overnight for removal of any adsorbates. Specific surface areas were determined according to the BET model.

XPS investigations. The measurement was performed on a Thermo Fisher Scientific NEXSA spectrometer. The samples were analysed using a micro-focused monochromatic Al X-ray source $(72 \mathrm{~W})$ over an area of approximately 400 microns. Data were recorded at the pass energies of $200 \mathrm{eV}$ for survey scans $(1.0 \mathrm{eV}$ step) and $50 \mathrm{eV}$ for the high-resolution scans ( $0.1 \mathrm{eV}$ step). Charge neutralisation of the sample was achieved using a combination of both low energy electrons and argon ions. C $1 s$ electron at $284.8 \mathrm{eV}$ was used as the standard reference to calibrate the photoelectron energy shift. XPS spectra in Ce $3 d$ region from 840 to $940 \mathrm{eV}$ was collected and fitted to identify the ratio of Ce in different oxidation states. Data analysis were performed on the CasaXPS software (version: 2.3.18PR1.0).

Catalytic tests. The catalytic performance in $\mathrm{CO}$ oxidation was evaluated on a FD2000 fix-bed reactor (Huasi, China). Approximately, $10-100 \mathrm{mg}$ catalyst powder was packed into a quartz tube. A mixture of gases ( $1 \mathrm{vol} \% \mathrm{CO}, 10 \mathrm{vol} \% \mathrm{O}_{2}, 89 \mathrm{vol} \%$ $\mathrm{N}_{2}$ ) was introduced to the reactor via 4 MFCs. The exhaust gas was analysed by AO2000 Series Advance Optima Continuous Gas Analyser (ABB, Germany) equipped with three individual sensors: IR spectrometer for $\mathrm{CO}$ and $\mathrm{CO}_{2}$, superparamagnetic $\mathrm{O}_{2}$ analyser and thermal conductivity detector for $\mathrm{H}_{2}$.

CO-TPR and CO-TPD investigations. The measurements were performed on the same FD-2000 reactor. Typically, $100 \mathrm{mg} \mathrm{CuO}-\mathrm{CeO}_{2}$ was put into a quartz tube. The content of $\mathrm{CO}$ and $\mathrm{CO}_{2}$ in the exhaust gas was quantified by the same $\mathrm{AO} 2000$ analyser. To remove any potential carbon contamination, the sample was preoxidised in $100 \mathrm{~mL} / \mathrm{min} 5 \% \mathrm{O}_{2} / \mathrm{He}$ at $673 \mathrm{~K}$ for 30 mins. After oxidation, the sample was cooling down to room temperature in He. For CO-TPR, the sample was kept in $2 \% \mathrm{CO} / \mathrm{N}_{2}$ flow $(100 \mathrm{~mL} / \mathrm{min})$ and heated up to $473 \mathrm{~K}$ with a rate at $5 \mathrm{~K} / \mathrm{min}$. For CO-TPD, the sample adsorbed CO in $2 \% \mathrm{CO} / \mathrm{N}_{2}(100 \mathrm{~mL} / \mathrm{min})$ at room temperature for $30 \mathrm{~min}$ and was blown with $\mathrm{He}(100 \mathrm{~mL} / \mathrm{min})$ for another $30 \mathrm{~min}$ to remove physically adsorbed $\mathrm{CO}$. The $\mathrm{CO}$ adsorbed sample was then heated up to $673 \mathrm{~K}$ in He with a rate at $5 \mathrm{~K} / \mathrm{min}$. 
NAP-NEXAFS investigations. In situ NAP-NEXAFS experiments were accomplished at the ISISS beamline of BESSY II in Berlin (Germany). The X-ray is sourced from a bending magnet (D41) and a plane grating monochromator (PGM) with an energy range from 80 to $2000 \mathrm{eV}$ (soft X-ray range) and flux of $6 \times 10^{10}$ photons/s with $0.1 \mathrm{~A}$ ring current using a $111 \mu \mathrm{m}$ slit and an $80 \mu \mathrm{m} \times 200 \mu \mathrm{m}$ beam spot size. The in situ measurements were accomplished in the ambient pressure $\mathrm{X}$ ray end-station using a Faraday-cup to collect the NEXAFS spectra in the O K-edge and $\mathrm{Cu} \mathrm{L}$-edge at different partial pressures. The reaction products were online monitored using an electron impact mass spectrometer ("PRISMA", PFEIFFER VACUUM GmbH, Asslar (Germany)) connected directly to the main experimental chamber by a leak valve. The pressure in the specimen chamber was precisely controlled (UHV or 0.1-1 mbar) by simultaneous operations of several mass flow controllers for reactive gases and a PID-controlled throttle valve for pumping gas out. Sample pellets ( $8 \mathrm{~mm}$ diameter) was heated uniformly from the back side by a focused infra-red laser. A stainless-steel plate was placed behind the pellet to improve the heat transfer. The temperature was monitored by a K-type thermocouple and regulated by a PID controller connected to the laser power source.

NEXAFS spectra at $\mathrm{Cu} \mathrm{L}_{3} / \mathrm{L}_{2}$ edge (920-960 eV), Ce $\mathrm{M}_{5} / \mathrm{M}_{4}$ edge (860-920 eV) and $\mathrm{O}$ K-edge $(520-560 \mathrm{eV})$ were measured in either total electron yield (TEY) mode or Auger electron yield (AEY) mode. AEY mode, which has a worse signal to noise ratio compared with TEY mode, was only used for the O K-edge measurement to avoid gas phase absorption signal while gas-phase $\mathrm{O}_{2}$ or $\mathrm{CO}$ was present. The excitation energy scale was calibrated for the $\mathrm{Cu}$ L-edge using the absorption edge of metallic $\mathrm{Cu}(932.67 \mathrm{eV}$ at the adsorption edge inflexion point). In the case of the O K-edge, it was calibrated using the $\pi^{*}$ transition of gas-phase $\mathrm{O}_{2}$ (absorption peak at $530.8 \mathrm{eV}$ ).

Computational methods. Spin-polarised DFT $+U$ calculations were carried out with the generalised gradient approximation with the Perdew-Burke-Ernzerhof (GGA-PBE) functional using the Vienna Ab initio Simulation Package (VASP) ${ }^{64,65}$. The projector augmented wave (PAW) pseudopotentials were employed to describe the electron-core interaction ${ }^{66,67}$. The wave functions were expanded in plane waves with a kinetic energy cut-off of $400 \mathrm{eV}$ for all calculations. The $U$ value for the Coulomb interaction correction was set to $5.0 \mathrm{eV}$ to describe the electronic property of Ce appropriately. The calculated lattice parameters of bulk ceria using the DFT $+U$ method $(5.448 \AA)$ is in good agreement with the experimental value $(5.411 \AA)$. The $\mathrm{CeO}_{2}(111)$ surface was modelled using a nineatomic-layer slab with the $p(3 \times 3)$ supercell. The bottom three layers were fixed at the bulk parameters, while the upper six layers were allowed to fully relax. The $\mathrm{CeO}_{2}(110)$ surface was modelled using a nine-atomic-layer slab with the $p(2 \times 2)$ supercell. The bottom three layers were fixed at the bulk parameters, while the upper six layers were allowed to fully relax. The $\mathrm{CeO}_{2}(100)$ surface was modelled using an eight-atomic-layer slab with the $p(2 \times 2)$ supercell. The bottom two layers were fixed at the bulk parameters, while the upper six layers were allowed to fully relax. The $\mathrm{CuO}(111)$ and $\mathrm{Cu}_{2} \mathrm{O}(111)$ surfaces were constructed using $p(2 \times 2)$ supercell with four layers, in which the bottom two layers were fixed and the upper two layers were fully relaxed. A vacuum region of $15 \AA$ was used for all surface models in order to remove the interactions between the periodic images along the $c$-axes. The $\mathrm{CeO}_{2}(111)$ surface is selected as the representative support for the $\mathrm{Cu}$ single-sites. To simulate the $\mathrm{Cu}(\mathrm{I} / \mathrm{II})$ single-sites, two models are constructed based on their structures in the forms of $\left[\mathrm{Cu}(\mathrm{I}) \mathrm{O}_{2}\right]^{3-}$ and $\left[\mathrm{Cu}(\mathrm{II}) \mathrm{O}_{4}\right]^{6-}$, which are identified by in situ XAFS (Fig. 5). In the model for $\left[\mathrm{Cu}(\mathrm{I}) \mathrm{O}_{2}\right]^{3-}$ site, an initial neutral $\mathrm{Cu}$ atom is put on $\mathrm{CeO}_{2}(111)$ surface and coordinates with two lattice oxygen atoms in $\mathrm{CeO}_{2}$. As revealed by the NAP-NEXAFS, the $\left[\mathrm{Cu}(\mathrm{I}) \mathrm{O}_{2}\right]^{3-}$ site can adsorb one $\mathrm{O}_{2}$ molecule and evolve into the $\left[\mathrm{Cu}(\mathrm{II}) \mathrm{O}_{4}\right]^{6-}$ site (Fig. 4). In the model for $\left[\mathrm{Cu}(\mathrm{II}) \mathrm{O}_{4}\right]^{6-}$ site, there are four $\mathrm{Cu}-\mathrm{O}$ bonds in total to stabilise the structure and maintain the +2 oxidation states. The two $\mathrm{O}$ atoms provided by $\mathrm{CeO}_{2}$ support are inherited from the $\left[\mathrm{Cu}(\mathrm{I}) \mathrm{O}_{2}\right]^{3-}$ structure (adding $\mathrm{Cu}$ atom on $\mathrm{CeO}_{2}$ surface) whereas the other two $\mathrm{Cu}-\mathrm{O}$ bonds are introduced by the adsorption of molecular $\mathrm{O}_{2}$ which is available in the reaction gas. There are four $\mathrm{Ce}-\mathrm{O}-\mathrm{Cu}$ bridges. The calculation shows the formation of additional two $\mathrm{Ce}-\mathrm{O}$ bonds in $\left[\mathrm{Cu}(\mathrm{II}) \mathrm{O}_{4}\right]^{6-}$ structure origins from the cleavage of the $\mathrm{O}-\mathrm{O}$ bond in $\left[\mathrm{Cu}(\mathrm{II}) \mathrm{O}_{2}\left(\eta^{2}-\mathrm{O}_{2}\right)\right]^{4-}$ (Supplementary Fig. 27). As a result, the newly formed $\mathrm{Cu}-\mathrm{O}-\mathrm{Ce}$ bridges give similar signals to that of lattice oxygen species in the $\mathrm{O} \mathrm{K}$ edge NAP-NEXAFS (Fig. 4d, right). All calculations were converged until the force on each atom was less than $0.02 \mathrm{eV}^{-1}$. The Brillouin zone integration was performed using a $2 \times$ $2 \times 1$ Monkhorst-Pack (MP) k-points for surface structure optimisations and transition state (TS) calculations, while a $12 \times 12 \times 1 \mathrm{MP}$ k-points for the Bader charge analysis and charge density difference calculations. The adsorption energy $\left(E_{\text {ads }}\right)$ was defined as $E_{\text {ads }}=E_{\text {total }}-E_{\text {adsorbate }}-E_{\text {slab }}$, with $E_{\text {adsorbate, }}, E_{\text {slab }}$ and $E_{\text {total }}$ denoting the total energy of the adsorbate, the surface, and the complex of surface and adsorbate respectively. The TS was located by the climbing image nudged elastic band method ${ }^{68,69}$. The effective charges $\left(Q_{\mathrm{X}}\right)$ were calculated by Bader's charge population analysis with the equation: $Q_{\mathrm{X}}=Z_{\mathrm{X}}-q_{\mathrm{Bader}, \mathrm{X}}$, with $Z_{\mathrm{X}}$ and $q_{\mathrm{Bader}, \mathrm{X}}$ denoting the number of valence electrons and the calculated Bader charge of $\mathrm{X}$ atom, respectively.

\section{Data availability}

More experimental details and additional data can be found in the Supplementary Information (Supplementary Figs. 1-29, Supplementary Tables 1-13 and Supplementary
Notes 1 and 2). The data that support the findings of this study are available from the corresponding authors B.W. (email: bolun.wang@ucl.ac.uk) or F.R.W. (email: ryan. wang@ucl.ac.uk) upon reasonable request.

Received: 9 October 2019; Accepted: 22 July 2020; Published online: 11 August 2020

\section{References}

1. Norskov, J. K. et al. Origin of the overpotential for oxygen reduction at a fuelcell cathode. J. Phys. Chem. B 108, 17886-17892 (2004).

2. Hammer, B. \& Norskov, J. K. Electronic factors determining the reactivity of metal surfaces. Surf. Sci. 343, 211-220 (1995).

3. Cargnello, M. et al. Exceptional activity for methane combustion over modular Pd@CeO2 subunits on functionalized Al2O3. Science 337, 713-717 (2012).

4. Stamenkovic, V. R. et al. Improved oxygen reduction activity on $\mathrm{Pt} 3 \mathrm{Ni}(111)$ via increased surface site availability. Science 315, 493-497 (2007).

5. Hernandez-Fernandez, P. et al. Mass-selected nanoparticles of PtxY as model catalysts for oxygen electroreduction. Nat. Chem. 6, 732-738 (2014).

6. Turner, M. et al. Selective oxidation with dioxygen by gold nanoparticle catalysts derived from 55-atom clusters. Nature 454, 981-983 (2008).

7. Lei, Y. et al. Increased silver activity for direct propylene epoxidation via subnanometer size effects. Science 328, 224-228 (2010).

8. Hua, Q. et al. Crystal-plane-controlled selectivity of $\mathrm{Cu} 2 \mathrm{O}$ catalysts in propylene oxidation with molecular oxygen. Angew. Chem. Int. Ed. 53, 4856-4861 (2014)

9. Kesavan, L. et al. Solvent-free oxidation of primary carbon-hydrogen bonds in toluene using Au-Pd alloy nanoparticles. Science 331, 195-199 (2011).

10. Agarwal, N. et al. Aqueous Au-Pd colloids catalyze selective $\mathrm{CH} 4$ oxidation to $\mathrm{CH} 3 \mathrm{OH}$ with $\mathrm{O} 2$ under mild conditions. Science 358, 223-226 (2017).

11. Arpe, H.-J. \& Weissermel, K. Oxidation products ethylene. in: Industrial Organic Chemistry (eds Arpe, H.-J. \& Weissermel, K.) 145-192 (Wiley-VCH, 2010).

12. Ruban, A., Hammer, B., Stoltze, P., Skriver, H. L. \& Norskov, J. K. Surface electronic structure and reactivity of transition and noble metals. J. Mol. Catal. A. Chem. 115, 421-429 (1997).

13. Zhao, Z. J., Chiu, C. C. \& Gong, J. L. Molecular understandings on the activation of light hydrocarbons over heterogeneous catalysts. Chem. Sci. 6, 4403-4425 (2015)

14. Trovarelli, A. Catalytic properties of ceria and $\mathrm{CeO} 2$-containing materials. Catal. Rev. 38, 439-520 (1996).

15. Liu, W. \& Flytzani-Stephanopoulos, M. Total oxidation of carbon-monoxide and methane over transition metal-fluorite oxide composite catalysts. 1 . catalyst composition and activity. J. Catal. 153, 304-316 (1995).

16. Martinez-Arias, A. et al. Comparative study on redox properties and catalytic behavior for $\mathrm{CO}$ oxidation of $\mathrm{CuO} / \mathrm{CeO} 2$ and $\mathrm{CuO} / \mathrm{ZrCeO} 4$ catalysts. J. Catal. 195, 207-216 (2000).

17. Paolucci, C. et al. Dynamic multinuclear sites formed by mobilized copper ions in NOx selective catalytic reduction. Science 357, 898-903 (2017).

18. Godiksen, A., Vennestrom, P., Rasmussen, S. \& Mossin, S. Identification and quantification of copper sites in zeolites by electron paramagnetic resonance spectroscopy. Top. Catal. 60, 13-29 (2017).

19. Gunter, T. et al. Structural snapshots of the SCR reaction mechanism on $\mathrm{Cu}-$ SSZ-13. Chem. Commun. 51, 9227-9230 (2015).

20. Hoover, J. M., Ryland, B. L. \& Stahl, S. S. Mechanism of copper(I)/TEMPO catalyzed aerobic alcohol oxidation. J. Am. Chem. Soc. 135, 2357-2367 (2013)

21. Zhang, M. T., Chen, Z. F., Kang, P. \& Meyer, T. J. Electrocatalytic water oxidation with a copper(II) polypeptide complex. J. Am. Chem. Soc. 135, 2048-2051 (2013).

22. Pham, A. N., Xing, G. W., Miller, C. J. \& Waite, T. D. Fenton-like copper redox chemistry revisited: Hydrogen peroxide and superoxide mediation of copper-catalyzed oxidant production. J. Catal. 301, 54-64 (2013).

23. Cramer, C. J. \& Tolman, W. B. Mononuclear $\mathrm{CuO} 2$ complexes: geometries, spectroscopic properties, electronic structures, and reactivity. Acc. Chem. Res 40, 601-608 (2007)

24. Holland, P. L. Metal-dioxygen and metal-dinitrogen complexes: where are the electrons? Dalton Trans. 39, 5415-5425 (2010).

25. Aboelella, N. W. et al. Snapshots of dioxygen activation by copper: the structure of a $1: 1 \mathrm{Cu} / \mathrm{O} 2$ adduct and its use in syntheses of asymmetric bis (mu-oxo) complexes. J. Am. Chem. Soc. 124, 10660-10661 (2002).

26. Yang, X. F. et al. Single-atom catalysts: a new frontier in heterogeneous catalysis. Acc. Chem. Res. 46, 1740-1748 (2013).

27. Liu, L. C. \& Corma, A. Metal catalysts for heterogeneous catalysis: from single atoms to nanoclusters and nanoparticles. Chem. Rev. 118, 4981-5079 (2018). 
28. Wang, X. Q. et al. In situ studies of the active sites for the water gas shift reaction over $\mathrm{Cu}-\mathrm{CeO} 2$ catalysts: complex interaction between metallic copper and oxygen vacancies of ceria. J. Phys. Chem. B 110, 428-434 (2006).

29. Greiner, M. T. et al. Free-atom-like d states in single-atom alloy catalysts. Nat. Chem. 10, 1008-1015 (2018)

30. Lee, B. H. et al. Reversible and cooperative photoactivation of single-atom Cu/ TiO2 photocatalysts. Nat. Mater. 18, 620-626 (2019).

31. Bukhtiyarov, V. I. et al. Combined in situ XPS and PTRMS study of ethylene epoxidation over silver. J. Catal. 238, 260-269 (2006).

32. Rocha, T. C. R., Hävecker, M., Knop-Gericke, A. \& Schlögl, R. Promoters in heterogeneous catalysis: the role of $\mathrm{Cl}$ on ethylene epoxidation over Ag. J. Catal. 312, 12-16 (2014)

33. Kydd, R. et al. Flame-synthesized ceria-supported copper dimers for preferential oxidation of CO. Adv. Funct. Mater. 19, 369-377 (2009).

34. Mädler, L., Stark, W. J. \& Pratsinis, S. E. Flame-made ceria nanoparticles. J. Mater. Res. 17, 1356-1362 (2002).

35. Gaur, A. et al. Identification of different coordination geometries by XAFS in copper(II) complexes with trimesic acid. J. Mol. Struct. 1121, 119-127 (2016).

36. Gaur, A. \& Shrivastava, B. D. A comparative study of the methods of speciation using X-ray absorption fine structure. Acta Phys. Pol. A 121 , 647-652 (2012).

37. Soria, J., Conesa, J. C., Martinezarias, A. \& Coronado, J. M. ESR study of the clustering of $\mathrm{Cu}$ ions on the ceria surface in impregnated $\mathrm{CuO} / \mathrm{CeO} 2$. Solid State Ion. 63-65, 755-761 (1993).

38. Soria, J., Martinez-Arias, A., Martinez-Chaparro, A., Conesa, J. C. \& Schay, Z. Influence of the preparation method, outgassing treatment, and adsorption of $\mathrm{NO}$ and/or $\mathrm{O} 2$ on the Cu2+ species in Cu-ZSM-5: an EPR study. J. Catal. 190, 352-363 (2000).

39. Aboukais, A. et al. Highly resolved electron-paramagnetic resonance-spectrum of copper(II) ion-pairs in CuCe oxide. J. Chem. Soc. Faraday Trans. 88, 615-620 (1992).

40. Kais, A. A., Bennani, A., Aissi, C. F., Wrobel, G. \& Guelton, M. Reduction effect on cerium oxide catalysts doped with copper(II) ions-an electronparamagnetic resonance study. J. Chem. Soc. Faraday Trans. 88, 1321-1325 (1992).

41. Martinez-Arias, A., Fernandez-Garcia, M., Soria, J. \& Conesa, J. C. Spectroscopic study of a $\mathrm{Cu} / \mathrm{CeO} 2$ catalyst subjected to redox treatments in carbon monoxide and oxygen. J. Catal. 182, 367-377 (1999).

42. Kucherov, A. V. et al. Cu2 + cation location and reactivity in mordenite and ZSM-5: ESR-Study. Zeolites 5, 320-324 (1985).

43. Gao, F. et al. Understanding ammonia selective catalytic reduction kinetics over Cu/SSZ-13 from motion of the Cu ions. J. Catal. 319, 1-14 (2014).

44. Yao, S. Y. et al. Unraveling the dynamic nature of a $\mathrm{CuO} / \mathrm{CeO} 2$ catalyst for CO oxidation in operando: a combined study of XANES (fluorescence) and DRIFTS. ACS Catal. 4, 1650-1661 (2014).

45. Nie, L. et al. Activation of surface lattice oxygen in single-atom $\mathrm{Pt} / \mathrm{CeO} 2$ for low-temperature CO oxidation. Science 358, 1419-1423 (2017).

46. Greiner, M. T. et al. Phase coexistence of multiple copper oxides on $\mathrm{AgCu}$ catalysts during ethylene epoxidation. ACS Catal. 8, 2286-2295 (2018)

47. Greiner, M. T. et al. The oxidation of copper catalysts during ethylene epoxidation. Phys. Chem. Chem. Phys. 17, 25073-25089 (2015)

48. Krishnan, A., Sreeremya, T. S., Murray, E. \& Ghosh, S. One-pot synthesis of ultra-small cerium oxide nanodots exhibiting multi-colored fluorescence. $J$. Colloid Interface Sci. 389, 16-22 (2013).

49. Holgado, J. P., Alvarez, R. \& Munuera, G. Study of CeO2 XPS spectra by factor analysis: reduction of CeO2. Appl. Surf. Sci. 161, 301-315 (2000).

50. Paier, J., Penschke, C. \& Sauer, J. Oxygen defects and surface chemistry of ceria: quantum chemical studies compared to experiment. Chem. Rev. 113, 3949-3985 (2013).

51. McFarland, E. W. \& Metiu, H. Catalysis by doped oxides. Chem. Rev. 113, 4391-4427 (2013)

52. Chutia, A. et al. The adsorption of $\mathrm{Cu}$ on the $\mathrm{CeO} 2(110)$ surface. Phys. Chem. Chem. Phys. 19, 27191-27203 (2017).

53. Wang, F. et al. In situ EPR study of the redox properties of $\mathrm{CuO}-\mathrm{CeO} 2$ catalysts for preferential CO oxidation (PROX). ACS Catal. 6, 3520-3530 (2016).

54. DeRita, L. et al. Structural evolution of atomically dispersed Pt catalysts dictates reactivity. Nat. Mater. 18, 746-751 (2019).

55. Dent, A. J. et al. Performance of B18, the core EXAFS bending magnet beamline at Diamond. J. Phys. 430, 012023-012029 (2013).

56. Dent, A. J. et al. B18: a core XAS spectroscopy beamline for Diamond. J. Phys. 190, 012039-012042 (2009).

57. Diaz-Moreno, S. et al. The spectroscopy village at diamond light source. $J$. Synchrotron Radiat. 25, 998-1009 (2018).

58. Diaz-Moreno, S. et al. I20; the versatile X-ray absorption spectroscopy beamline at diamond light source. J. Phys. 190, 012038 (2009).
59. Hayama, S. et al. The scanning four-bounce monochromator for beamline I20 at the Diamond Light Source. J. Synchrotron Radiat. 25, 1556-1564 (2018).

60. Ravel, B. \& Newville, M. Athena, artemis, hephaestus: data analysis for X-ray absorption spectroscopy using IFEFFIT. J. Synchrotron Radiat. 12, 537-541 (2005).

61. Stoll, S. \& Schweiger, A. EasySpin, a comprehensive software package for spectral simulation and analysis in EPR. J. Magn. Reson. 178, 42-55 (2006).

62. Thompson, S. P. et al. Beamline I11 at Diamond: a new instrument for high resolution powder diffraction. Rev. Sci. Instrum. 80, 075107 (2009).

63. Thompson, S. P. et al. Fast X-ray powder diffraction on I11 at Diamond. J. Synchrotron Radiat. 18, 637-648 (2011).

64. Kresse, G. \& Furthmuller, J. Efficient iterative schemes for ab initio totalenergy calculations using a plane-wave basis set. Phys. Rev. B 54, 11169-11186 (1996).

65. Perdew, J. P., Burke, K. \& Ernzerhof, M. Generalized gradient approximation made simple. Phys. Rev. Lett. 77, 3865-3868 (1996).

66. Blochl, P. E. Projector augmented-wave method. Phys. Rev. B 50, 17953-17979 (1994).

67. Kresse, G. \& Joubert, D. From ultrasoft pseudopotentials to the projector augmented-wave method. Phys. Rev. B 59, 1758-1775 (1999).

68. Henkelman, G., Uberuaga, B. P. \& Jonsson, H. A climbing image nudged elastic band method for finding saddle points and minimum energy paths. $J$. Chem. Phys. 113, 9901-9904 (2000).

69. Henkelman, G. \& Jonsson, H. Improved tangent estimate in the nudged elastic band method for finding minimum energy paths and saddle points. J. Chem. Phys. 113, 9978-9985 (2000).

\section{Acknowledgements}

The project is funded by EPSRC (EP/P02467X/1 and EP/S018204/1), Royal Society (RG160661 and IES\R3\170097), the Newton International Fellowship (NF170761). We acknowledge Diamond Light Source beamtime (EM17559, SP17377, SP24285, NT15763, EM19318 and EM19246) and the UK Catalysis Hub block allocation for beamtime (SP15151 and SP19850). We acknowledge Helmholz-Zentrum Berlin for the beamtime in BESSY II (18207435-ST and 19108389-ST). We acknowledge SPring-8 for the operando XAFS experiments conducted under the proposal no. 2019A1533. The UK Catalysis Hub is kindly thanked for resources and support provided via our membership of the UK Catalysis Hub Consortium and funded by EPSRC (grants EP/ K014706/2, EP/K014668/1, EP/K014854/1, EP/K014714/1 and EP/M013219/1). This research has been performed with the use of facilities at the Research Complex at Harwell including MP-AES equipment. The authors would like to thank the Research Complex for access and support to these facilities and equipment. XPS data collection were performed at the EPSRC National Facility for XPS ('HarwellXPS'), operated by Cardiff University and UCL, under contract No. PR16195. The support of the Max Planck Society and the Slovak Scientific Grant Agency VEGA (1/0466/18) are also acknowledged.

\section{Author contributions}

L.K., B.W. and F.R.W. conceived the study. B.W., R.B. and S.E.P. carried out materials synthesis. L.K. performed materials characterisation and catalytic evaluations. Q.B. and J. Y.L. carried out the theoretical calculations. L.K., B.W., R.X., Q.W., D.G., E.G. and F.R.W performed ex situ and operando XAS study. L.K., B.W., S.M., J.V.V. and F.R.W. conducted the NAP-NEXAFS study. L.K., M.D., C.A. and Q.H. conducted the STEM measurement. K.W. and L.D.S. performed Raman analysis. S.G. conducted the XPS measurement. Y.L., M.Z., A.S. C.K. and W.L. conducted the ex situ and in situ EPR study and analysis. C.C.T. measured the SXRD. J.C. performed the MP-AES study. L.K., B.W. and F.R.W. wrote the paper and all authors revised the paper.

\section{Competing interests}

The authors declare no competing interests.

\section{Additional information}

Supplementary information is available for this paper at https://doi.org/10.1038/s41467 020-17852-8.

Correspondence and requests for materials should be addressed to B.W. or F.R.W.

Peer review information Nature Communications thanks Yuemin Wang and the other, anonymous, reviewer(s) for their contribution to the peer review of this work. Peer reviewer reports are available.

Reprints and permission information is available at http://www.nature.com/reprints

Publisher's note Springer Nature remains neutral with regard to jurisdictional claims in published maps and institutional affiliations. 
(c) (i) Open Access This article is licensed under a Creative Commons Attribution 4.0 International License, which permits use, sharing, adaptation, distribution and reproduction in any medium or format, as long as you give appropriate credit to the original author(s) and the source, provide a link to the Creative Commons license, and indicate if changes were made. The images or other third party material in this article are included in the article's Creative Commons license, unless indicated otherwise in a credit line to the material. If material is not included in the article's Creative Commons license and your intended use is not permitted by statutory regulation or exceeds the permitted use, you will need to obtain permission directly from the copyright holder. To view a copy of this license, visit http://creativecommons.org/ licenses/by/4.0/.

(C) The Author(s) 2020 